\title{
What's Happened to the Phillips Curve?
}

\author{
Flint Brayton, John M. Roberts, and John C. Williams* \\ Division of Research and Statistics \\ Federal Reserve Board \\ Washington, D.C. 20551
}

September 1999

\begin{abstract}
The simultaneous occurrence in the second half of the 1990s of low and falling price inflation and low unemployment appears to be at odds with the properties of a standard Phillips curve. We find this result in a model in which inflation depends on the unemployment rate, past inflation, and conventional measures of price supply shocks. We show that, in such a model, long lags of past inflation are preferred to short lags, and that with long lags, the NAIRU is estimated precisely but is unstable in the 1990s. Two alternative modifications to the standard Phillips curve restore stability. One replaces the unemployment rate with capacity utilization. Although this change leads to more accurate inflation predictions in the recent period, the predictive ability of the utilization rate is not superior to that of the unemployment rate for the 1955 to 1998 sample as a whole. The second, and preferred, modification augments the standard Phillips curve to include an "error-correction" mechanism involving the markup of prices over trend unit labor costs. With the markup relatively high through much of the 1990s, this channel is estimated to have held down inflation over this period, and thus provides an explanation of the recent low inflation.
\end{abstract}

Keywords: Inflation, NAIRU, Phillips curve.

\footnotetext{
${ }^{*}$ The authors acknowledge the comments and assistance of Peter Tulip and the comments of Robert Gordon and other participants at the 1999 NBER Summer Institute on Monetary Economics. Views presented are those of the authors and do not necessarily represent those of the Federal Reserve Board or its staff.
} 


\section{Introduction and Summary}

The rise and fall of inflation in the United States during the 1970s and 1980s provided a testing ground for the Phillips curve model of inflation dynamics. And, according to some observers (Fuhrer 1995, Gordon 1997), such models performed admirably well in tracking actual inflation, both within and out of sample. Based on this achievement, many became convinced of the usefulness of such models as tools in predicting inflation. Unfortunately, the main feature of empirical Phillips curve models, that is, that inflation rises when labor markets tighten, appears to be turned on its head during the economic expansion of the 1990s, when the unemployment rate fell below its long-run average of around 6 percent and then slid under 5 percent, while inflation fell.

One objective of this paper is to ascertain whether the recent performance of inflation is surprising in a statistical sense within the context of a canonical Phillips curve in which price inflation depends on the unemployment rate, past price inflation, and standard measures of price supply shocks. To provide a graphical preview of our conclusion that a significant shift likely has taken place in such a baseline model, figure 1 shows forecast errors for our preferred CPI equation. ${ }^{1}$ The upper panel of the figure contains one-quarterahead forecast errors based on successive reestimates of the equation over samples whose starting point is held fixed at 1955:Q1 and whose ending point advances one quarter at a time. The forecasts make use of the actual values of explanatory variables. ${ }^{2}$ While no individual error this decade lies outside of the 95 percent confidence range, inflation has consistently fallen short of the model's predictions over the past five years.

Given the run of negative prediction errors, multi-period forecast errors and their confidence bands provide a better graphical depiction of the probability of the equation's recent performance. The lower panel of the figure plots the sequence of four-quarter-ahead forecast errors. These errors are derived in a manner analogous to that used for the one-

\footnotetext{
${ }^{1}$ The inflation series is the the all-items CPI index, modified from 1967 to 1983 so that homeownership costs are on a rental-equivalent basis, and adjusted since 1995 to eliminate effects of methodological changes. The explanatory variables consist of twenty-four quarterly lags of past inflation; contemporaneous values of a demographically weighted unemployment rate and a composite measure of relative food and energy price movements; an intercept; and a variable for the 1970s wage-price controls. The structure of this equation is discussed in more detail below.

${ }^{2}$ The use of forecasts conditional on actual values of explanatory variables is appropriate because the issues being examined concern the structure of the Phillips curve itself. Errors in forecasting the unemployment rate, for example, are not germane because conceptually they are associated with the performance of other equations in a forecasting system.
} 
CPI Inflation: Forecast Errors

(observations dated by end of forecast interval)

(actual less predicted, annual rate)
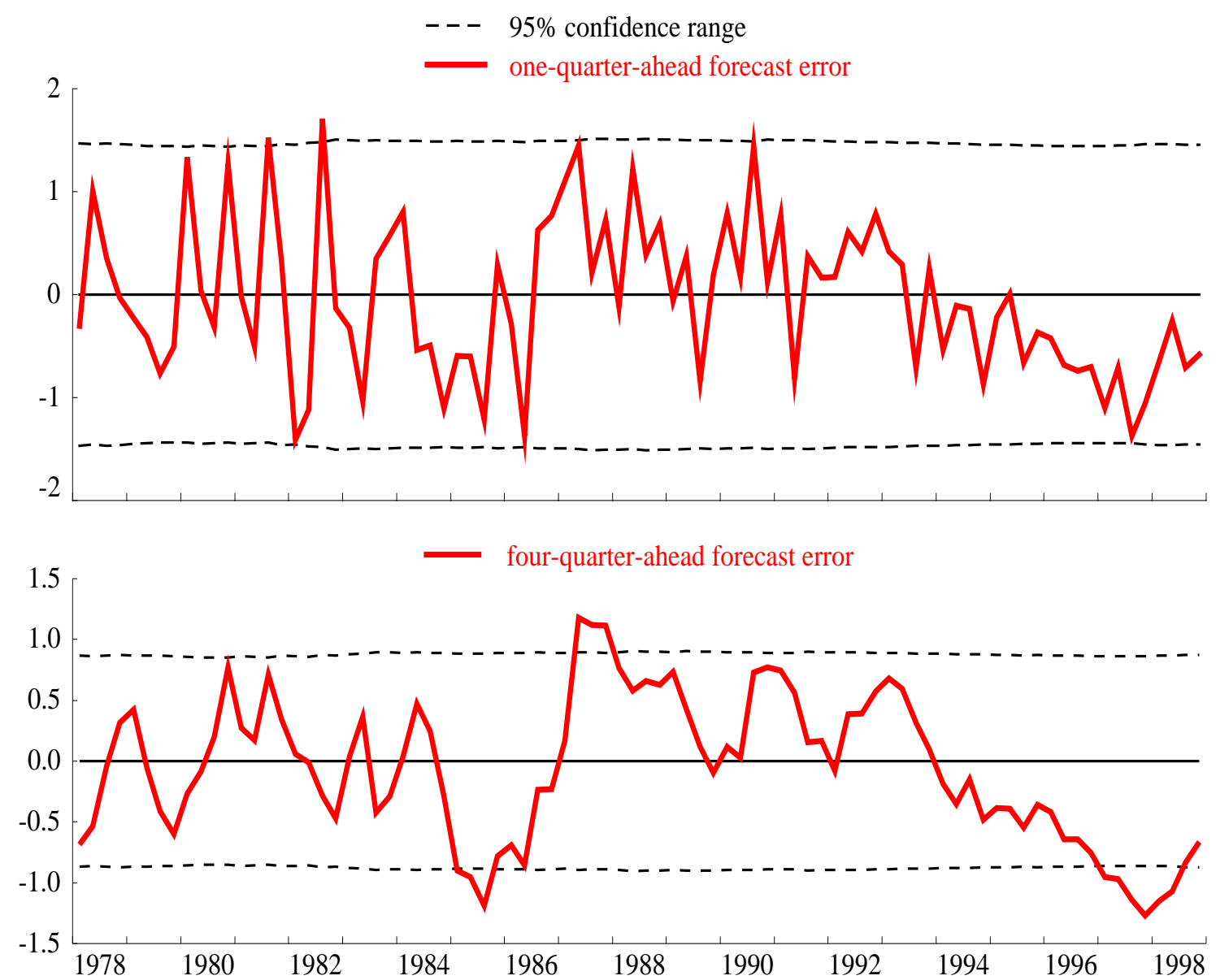
step-ahead errors, except that within each four-quarter forecast interval, the forecast is a dynamic simulation in which inflation lags are set equal to simulated values. The most recent four-quarter forecasts have overpredicted inflation by as much as 1.3 percentage points, well outside of the 95 percent confidence range, which encompasses forecast errors of up to 0.9 percentage points.

A tendency to overpredict inflation starting in the middle of this decade characterizes baseline equations for all six measures of inflation we study. For all but one, the magnitude of the prediction errors is sufficient to reject the hypothesis of stability of the equation's intercept at a significance level of 10 percent or lower. In the framework of these equations, instability of the intercept can be interpreted as instability of the NAIRU-that is, the rate of unemployment consistent with stable inflation (Non-Accelerating Inflation Rate of Unemployment).

We also find a close association between the number of lags of inflation included in the baseline equations and whether or not evidence of significant structural change is found. Equations such as ours with long inflation lags (up to twenty-four quarters) are generally unstable while those with short lags are not. In essence, estimates of the NAIRU are much more precise in long-lag equations than in short-lag equations, and consequently the level of the unemployment rate over the past few years is well below the 95 percent NAIRU confidence range of long-lag equations but not that of short-lag equations.

The relationship between inflation lag length and NAIRU precision has been documented by Staiger, Stock, and Watson (1997a)—hereafter, SSW-but they emphasize the wide confidence intervals for the NAIRU found in short-lag equations on grounds that such lag lengths are optimal according to either standard hypothesis tests or the use of information criteria to select lag lengths. Our long-lag equations are the outcome of using an information criteria to choose simultaneously lag lengths and coefficient smoothing restrictions. Permitting smoothing restrictions leads to equations that have much longer lags on past inflation than is the case when lag coefficients are unrestricted, but with only a few independently estimated parameters because the lag coefficients are restricted to lie on low-order polynomials. We show that these long-lag Phillips curves, in addition to yielding much more precise estimates of the NAIRU, have better out-of-sample forecasting properties than do the short-lag ones. Monte Carlo evidence indicates that the procedure of jointly searching over lag lengths and smoothing restrictions is reasonably accurate at finding the 
"correct" model, whether or not it contains smoothed inflation coefficients.

Our baseline analysis provides support for the type of Phillips curve long favored by Robert Gordon who for many years has reported a specification with twenty-four quarterly lags of past inflation. ${ }^{3}$ The tendency of our baseline equations to significantly overpredict inflation since the mid-1990s, however, is an indication of structural change-perhaps a decline of the NAIRU - or of misspecification. Because the baseline equations contain the relative rates of import price inflation and food and energy price inflation, the statistical evidence also permits the conclusion that recent declines in the relative prices of these supply variables are not sufficient to account fully for the low rate of inflation.

We investigate two possible explanations for the breakdown or near-breakdown of the standard Phillips curve. One is the possibility that the capacity utilization rate-which has been near its historical average during the past few years-is a better measure of macroeconomic slack than the unemployment rate, in which case the recent behavior of inflation would not be that extraordinary. From a conceptual perspective, the unemployment rate might be preferred because of its broader sectoral coverage. But as it turns out, movements of the utilization and unemployment rates are sufficiently similar over the past forty or so years that the goodness of fit of equations based on one is quite similar to the fit of equations based on the other. Nonetheless, we find that Phillips curve equations that include the unemployment rate fit somewhat better over the postwar years than do those using capacity utilization. The outcome is closer to a toss up in out-of-sample forecasts, however. All told, the evidence does not provide strong support for the use of capacity utilization but neither does it suggest that the utilization rate is dominated by the unemployment rate.

Our preferred explanation is based on an augmented Phillips curve that includes the level of the markup of price relative to trend unit labor costs as an error correction term. We find that the level of the markup in the nonfarm business sector is highly significant in equations for all measures of inflation examined, with a high markup estimated to restrain inflation and a low markup putting upward pressure on inflation. Equations that include the markup display much weaker evidence of instability. In particular, a high level of the markup in the mid-1990s is estimated to have depressed price inflation through the late 1990s.

\footnotetext{
${ }^{3}$ The most recent exposition is Gordon (1998).
} 


\title{
2 Baseline equations
}

We examine the performance of standard Phillips curves for six measures of inflation,

\author{
CPI Consumer price index, all items, \\ CPIX Consumer price index, excluding food and energy, \\ PCE Personal consumption expenditures chain-weight price \\ PCEX Personal consumption expenditures, excluding food and energy, \\ chain-weight price, \\ GDP GDP chain-weight price, \\ NFB Nonfarm business, excluding housing, chain-weight price,
}

over a sample period that extends most frequently from 1955:Q1 to 1998:Q4. Data availability limits the start of estimation periods for CPIX and PCEX equations to 1963:Q3 and 1965:Q3, respectively, after making allowance for the maximum number of inflation lags we consider.

A similar strategy of estimation and testing is applied to each measure of inflation. First, a list of potential explanatory variables is chosen, and then a data-based testing procedure is used to select which variables and how many lags to include in each inflation equation. Finally, to examine whether the inflation process has changed in some significant way, the coefficients of each estimated equation are tested for constancy using a procedure that does not require a prior belief about the precise date of the change.

\subsection{Selecting explanatory variables and lag lengths}

In the baseline specification, the list of potential explanatory variables consists of lags of inflation, a demographically weighted unemployment rate, and two measures of supply shocks: the rates of relative price inflation of imports and a food-energy aggregate. ${ }^{4}$ When initially considering how to determine lag lengths for explanatory variables, we noted that Gordon for many years has reported equations with twenty-four inflation lags while SSW (1997a) focus their attention on equations with only a year's worth of quarterly or monthly lags. These two specifications represent very different approaches to economizing on the number of freely estimated parameters on lagged inflation. Gordon achieves parsimony

\footnotetext{
${ }^{4}$ All equations also include a constant and a dummy variable for wage and price controls in the 1970 s.
} 
through the use of successive four-quarter averages of lags of inflation. Thus, his twentyfour lags require the estimation of only six coefficients (on lags 1-4, 5-8, etc.). SSW, on the other hand, estimate models in which each lag of inflation has a independent coefficient and frequently use an information criterion to choose the "best" number of lags.

Our method of choosing lag specification-on inflation, unemployment, and the two supply variables-draws on both of these approaches. Similar to SSW, we use an information criterion to choose optimal lag lengths. And in the spirit of Gordon, we permit smoothing of the lag coefficients, but by constraining the coefficients to lie on a polynomial function of the lag index-PDL restrictions. The Schwartz criterion is used to choose the optimal lag length and degree of PDL smoothing. ${ }^{5}$

A maximum of twenty-five lags of inflation is permitted, the unemployment rate and relative import price inflation may enter contemporaneously and with up to three lags, and relative food and energy price inflation may enter with up to four lags. The contemporaneous value of the food and energy price measure is excluded from CPIX and PCEX equations and included in the others. We constrain coefficients on lagged inflation to sum to one, a restriction that is consistent with the (near) unit root behavior of postwar inflation. Moreover, estimation of our equations without the restriction results in coefficient sums on lagged inflation that in all but a few instances are statistically and economically close to one.

Inflation data are adjusted to remove estimated effects of recent methodological changes in measuring consumer prices. ${ }^{6}$ The unemployment rate is a fixed-weight aggregate of unemployment rates of five age and gender categories using 1993 labor force shares. Definitions of the two supply variables vary by equation. For the four consumption price equations, a core measure of import prices is used that excludes oil, computers, and semiconductors. Oil is excluded because energy prices are taken account of through the other supply variable; and the small share of "high-tech" goods in personal consumption expenditures suggests excluding computers and semiconductors. The two product prices have bigger high-tech shares than does consumption, but the shares are still well short of the

\footnotetext{
${ }^{5}$ The large number of possible combinations of lag lengths and smoothing restrictions precludes a search of all combinations for the one with the smallest Schwartz criterion. Rather, we use an iterative procedure that alternates between finding the best specification of inflation lags, given the lag structure for unemployment and the supply variables, and finding the best specification of lags for unemployment and the supply variables, given the lag structure for inflation. The procedure starts by optimizing inflation lags while including the maximum number of lags permitted on the other variables without any coefficient smoothing restrictions.

${ }^{6} \mathrm{~A}$ description of all data series, including the adjustments to inflation, is provided in the appendix.
} 
contribution of such goods to imports. Roughly speaking, GDP has about one-tenth the computer and semiconductor share of imports. Consequently, the import price series we use in the product price equations includes one-tenth the contribution of computers and semiconductors to import prices. Relative import price inflation is constructed by subtracting from the appropriate measure of import price inflation the once-lagged value of the aggregate inflation series being explained. The second supply variable, relative food and energy price inflation, is measured as the difference between overall and core CPI inflation in the two CPI equations and as the difference between overall and core PCE inflation in the others. ${ }^{7}$

\subsection{Estimation results}

We present baseline Phillips curves estimated over two sample periods. The first set excludes the 1990s from the estimation period and serves as a point of reference in evaluating the second set, which is estimated through the end of 1998. Common to the Baseline-89 equations (table 1) are NAIRU estimates clustered around 6 percent with small standard errors that lie between 0.12 to 0.24 percentage points. ${ }^{8}$ Lag lengths on inflation are long (ranging from seventeen to twenty-five quarters) and coefficients on lagged inflation are highly smoothed. All equations include the relative price of food and energy, but only half contain import prices.

We find no evidence of coefficient instability at significance levels of 10 percent or smaller in the Baseline-89 equations for data through 1989. We test for two aspects of stability using the exponential $\mathrm{F}$ statistic for structural change at an unknown date. ${ }^{9}$ One is a joint test that all coefficients are stable; the other is for stability of the intercept, which in the baseline equations can be interpreted as examining the stability of the NAIRU. In the

\footnotetext{
${ }^{7}$ An adequate account of the short-run dynamics of NFB inflation also requires the inclusion of the contemporaneous value of relative farm sector price inflation to capture the tendency of NFB prices to move initially in the opposite direction of a change in the price of farm sector output. The NFB price is a valueadded measure whose construction entails the subtraction of farm prices, and so the negative relationship NFB and farm sector prices may represent either measurement error in farm prices or a tendency for the cost of farm sector inputs to not be immediately passed through to the price of finished food products.

${ }^{8}$ We measure standard errors of the NAIRU as one-half the width of the 70 percent confidence interval computed by the Gaussian method advocated by SSW (1997a).

${ }^{9}$ The exponential F statistic equals $\log \int \exp (.5 F(s)) d s$, where $\mathrm{F}$ is the value of the standard Chow test for coefficient stability at time s. Andrews, Lee, and Ploberger (1996) conclude that this test generally has properties that are superior to those of other tests for structural change at an unknown date. Critical values for the exponential F statistic are reported in Andrews and Ploberger (1994).
} 
Table 1: Baseline-89 Equations

\begin{tabular}{|lcccccc|}
\hline & CPI & PCE & CPIX & PCEX & GDP & NFB \\
\hline $\begin{array}{c}\text { Equation Specification: }^{a} \\
\text { inflation lags }\end{array}{ }^{\text {pdl degree }}$ & $25^{2}$ & $24^{2}$ & $24^{2}$ & $24^{2}$ & $19^{2}$ & $17^{2}$ \\
unemployment rate & $\mathrm{x}$ & $\mathrm{x}$ & $\mathrm{x}$ & $\mathrm{x}$ & $\mathrm{x}$ & $\mathrm{x}$ \\
& & $\mathrm{x}$ & $\mathrm{x}$ & $\mathrm{x}$ & $\mathrm{x}$ & $\mathrm{x}$ \\
food and energy price & $\mathrm{x}$ & & & & $\mathrm{x}$ & $\mathrm{x}$ \\
$\quad$ import price & & $\mathrm{x}$ & & & 5.94 & 5.90 \\
$\begin{array}{l}\text { NAIRU } \\
\text { (std. err. }{ }^{b} \text { ) }\end{array}$ & 6.05 & 6.04 & 6.19 & 6.30 & 5.94 \\
\end{tabular}

${ }^{a}$ Coefficient estimates and regression statistics are presented in the appendix.

${ }^{b}$ One-half of the 70 percent confidence range.

absence of a prior about the type of structural change that might have occurred, testing the stability of all coefficients simultaneously is appropriate. If we believe that any instability is confined to the constant term, however, the joint test has low power and the test of intercept stability is preferred.

From the point of view of 1989, an analyst would have been well justified in claiming that the Phillips curve was a stable relationship, with a constant NAIRU. We now consider whether the experience of the 1990s would leave the analyst equally sanguine. As shown in the top part of table 2, the longer sample generally has only minor effects on the preferred specifications. Inflation lag lengths become shorter in three instances, but the change is substantial only in the case of PCEX for which the lag length falls from twenty-four to ten quarters. Estimates of the NAIRU are slightly lower, but remain close to 6 percent, and have standard errors that, except for the PCEX equation, are little changed from those in the shorter sample. Import prices appear in four of six equations, rather than three.

As shown earlier, out-of-sample forecast errors for the baseline CPI equation indicate a persistent overprediction of the rate of inflation starting in 1994. We now formally test the stability of this equation over a time span that includes the period of surprisingly low inflation. Although many have come to believe that factors such as increased international competition or lower wage demands arising from heightened job insecurity have restrained inflation recently, our view is that these hypotheses have been motivated primarily by the ex post observation that inflation has been low relative to predictions. ${ }^{10}$ Moreover, the

\footnotetext{
${ }^{10}$ In a recent paper, Katz and Kreuger (1999) do not find any evidence that supports the worker insecurity
} 
Table 2: Baseline-98 Equations

\begin{tabular}{|c|c|c|c|c|c|c|}
\hline & $\mathrm{CPI}$ & PCE & CPIX & PCEX & GDP & NFB \\
\hline $\begin{array}{l}\text { Equation Specification: }^{a} \\
\text { inflation lags }\end{array}$ & $24^{2}$ & $24^{2}$ & $23^{2}$ & $10^{2}$ & $15^{2}$ & $17^{2}$ \\
\hline unemployment rate & $\mathrm{x}$ & $\mathrm{x}$ & $\mathrm{x}$ & $\mathrm{x}$ & $\mathrm{x}$ & $\mathrm{x}$ \\
\hline food and energy price & $\mathrm{x}$ & $\mathrm{x}$ & $\mathrm{x}$ & $\mathrm{x}$ & $\mathrm{x}$ & $\mathrm{x}$ \\
\hline import price & & $\mathrm{x}$ & & $\mathrm{x}$ & $\mathrm{x}$ & $\mathrm{x}$ \\
\hline $\begin{array}{l}\text { NAIRU } \\
\left.\quad \text { (std. err. }^{b}\right)\end{array}$ & $\begin{array}{l}5.98 \\
(.12)\end{array}$ & $\begin{array}{l}5.88 \\
(.15)\end{array}$ & $\begin{array}{l}5.99 \\
(.18)\end{array}$ & $\begin{array}{l}5.86 \\
(.30)\end{array}$ & $\begin{array}{l}5.88 \\
(.17)\end{array}$ & $\begin{array}{l}5.84 \\
(.19)\end{array}$ \\
\hline \multicolumn{7}{|l|}{ Stability tests: ${ }^{c}$} \\
\hline all coefficients & $* *$ & $* * *$ & - & - & $* *$ & - \\
\hline intercept only & $* * *$ & $* * *$ & $* *$ & - & $* *$ & $*$ \\
\hline \multicolumn{7}{|l|}{ NAIRU shift: ${ }^{d}$} \\
\hline most likely date & 94.4 & 95.1 & 93.3 & 92.2 & 95.2 & 97.3 \\
\hline pre-shift NAIRU & 6.09 & 6.06 & 6.21 & 6.17 & 6.01 & 5.93 \\
\hline post-shift NAIRU & 4.83 & 4.04 & 4.85 & 4.72 & 4.47 & 3.20 \\
\hline
\end{tabular}

${ }^{a}$ Coefficient estimates and regression statistics are presented in the appendix.

${ }^{b}$ One-half of the 70 percent confidence range.

${ }^{c}$ Significance level: $>.10(-), .10(*), .05(* *)$,or $.01(* * *)$.

${ }^{d}$ From the equation whose dating of an intercept shift yields the Chow statistic with the lowest p-value.

For GDP and NFB, the entries correspond to the lowest p-value after the 1950s. 
conjectures do not provide any independent information about the likely date of a shift in the inflation process. Thus, in the absence of a specific prior, we assess the stability of the CPI equation at all dates in the full estimation period, which runs from 1955:Q1 to 1998:Q4.

For the CPI equation, the test for stability of all coefficients rejects constancy at the 5 percent level, as shown in the bottom panel of table 2. An even stronger case for a shift in the Phillips curve is found when only the intercept is allowed to change. Here, the test indicates a probability of no shift that is less than 1 percent. Based on the shift date that provides the best fit (and for which the Chow statistic attains its lowest p-value), the shift in the intercept most likely occurred at 1994:Q4, with the NAIRU estimated to fall from 6.1 percent up until 1994 to 4.8 percent thereafter.

The other baseline inflation equations also tend to show instability of the intercept, with the probability of no structural change being less than 10 percent for NFB, less than 5 percent for CPIX and GDP, and less than 1 percent for PCE. In these equations, the most likely date for an intercept shift ranges from late 1992 to mid 1997, with the NAIRU estimated to fall from a bit higher than 6 percent to as low as 3.2 percent in the case of NFB to as high as 4.9 percent in the case of CPIX. Only the PCEX equation shows no evidence of a shift at a significance level of 10 percent.

\subsection{Other estimates of time variation of the NAIRU}

The baseline inflation equations tend to be structurally unstable and indicate that the NAIRU has declined in the 1990s. The assumption used to pin down the timing of the NAIRU shift - that it occurred in a single quarter — may be unrealistic, however. As a check on our results, we estimate variants of the baseline equations using two other statistical models of time variation in the NAIRU that have appeared in the recent literature on Phillips curves. Gordon $(1997,1998)$ and SSW (1997a) use the Kalman filter to estimate inflation equations in which the intercept follows a random walk, and SSW (1997a, 1997b) allow the intercept to move along a cubic spline.

Figure 2 compares estimates of the NAIRU based on the Kalman filter and cubic spline with the estimates derived from intercept shifts presented above. The Kalman filter series

hypothesis, but they do conclude that the NAIRU has fallen since the mid-1980s because of the rising fraction of the population in prison and the increasing size of the temporary help industry. 
Figure 2

\section{Time-Varying NAIRUs}

CPI

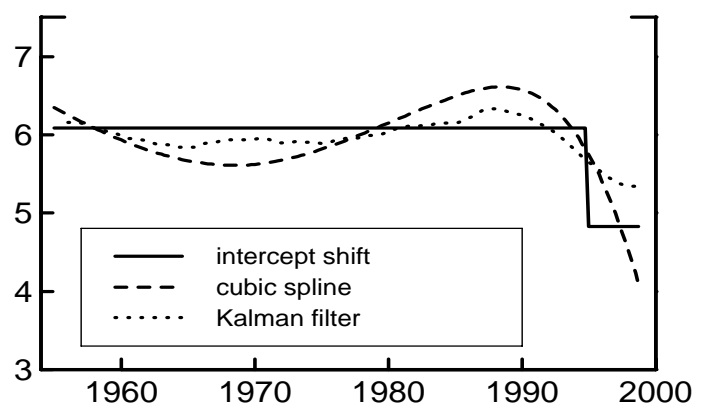

CPIX

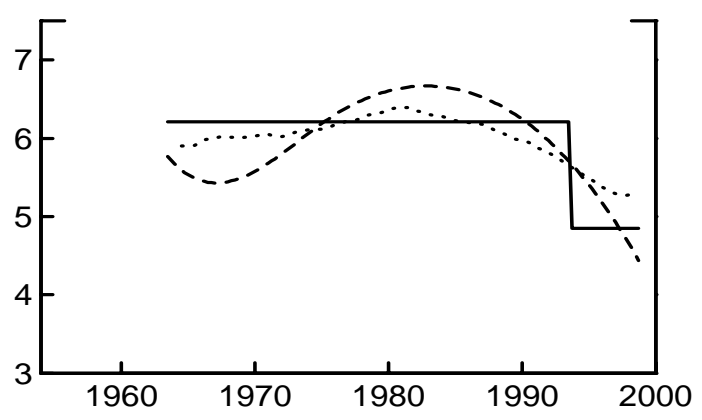

GDP

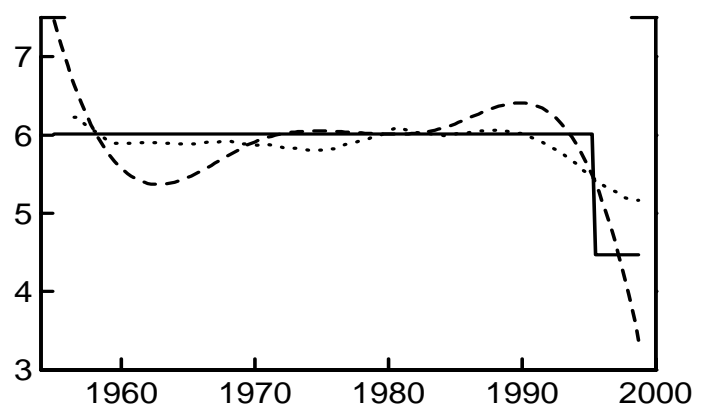

PCE
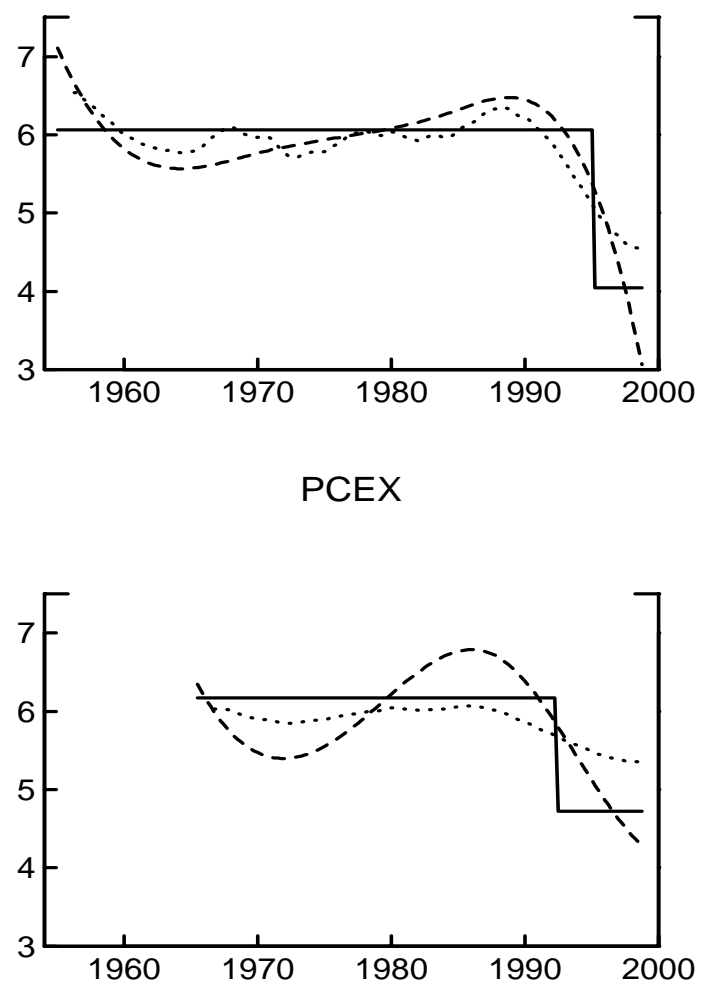

NFB

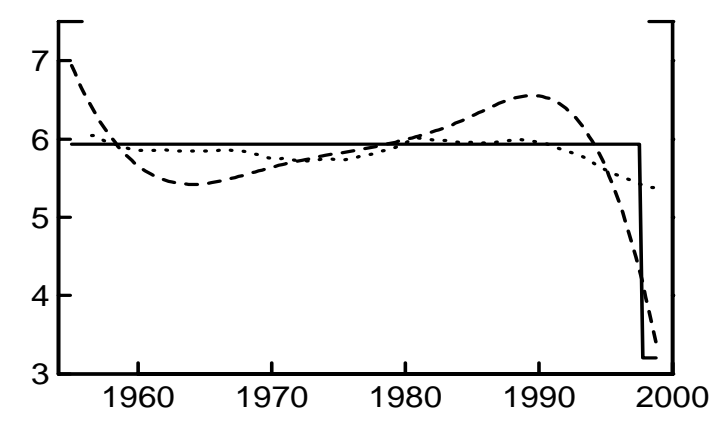


Figure 3

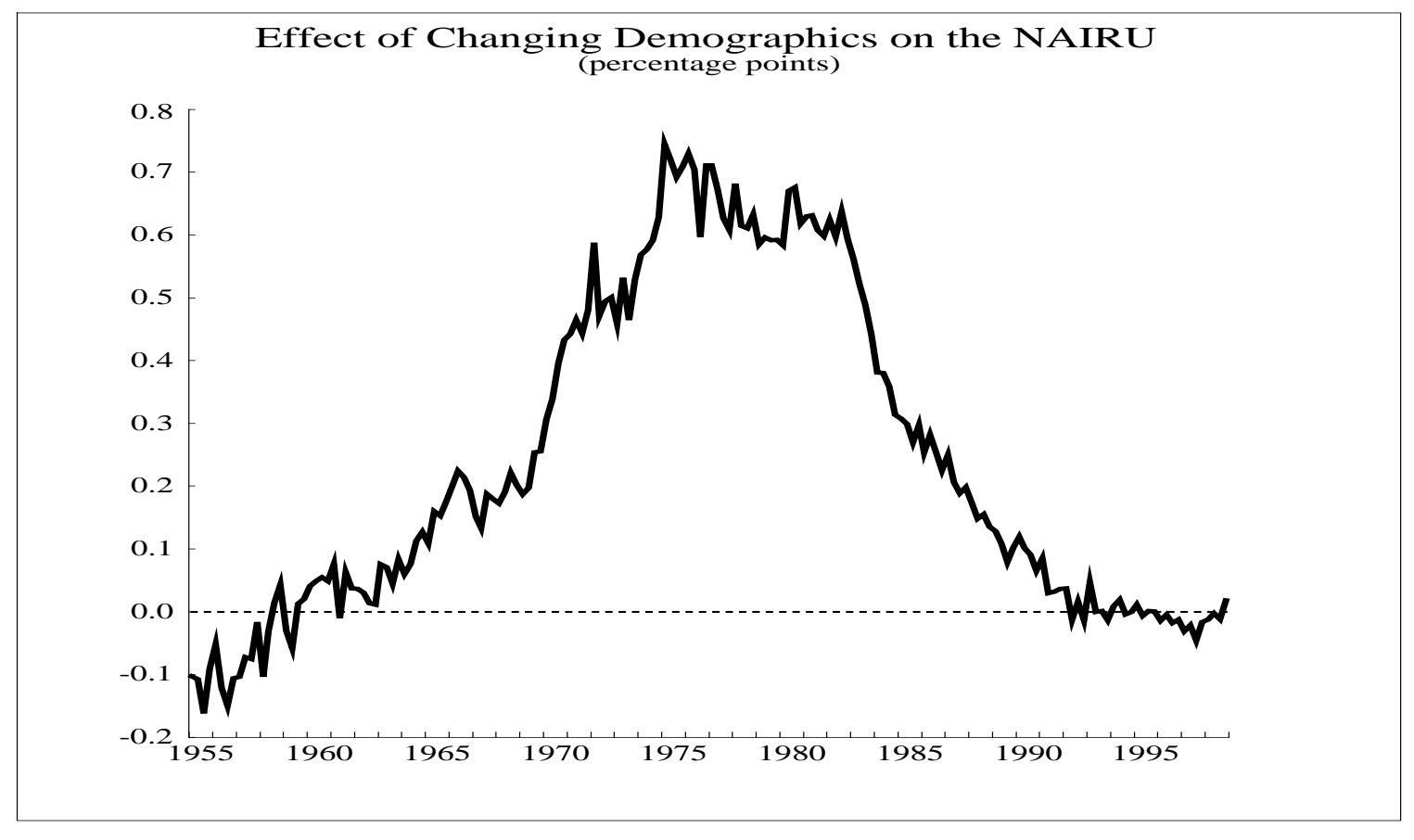

use the median unbiased estimate of the variance of the random walk component of the intercept of the Phillips curve. ${ }^{11}$ The cubic spline estimates assume two "knot" points whose location divides the estimation period into three segments of equal size. The unemployment rate entering the estimation equations is demographically weighted as are the values of the NAIRU plotted in figure 2. The Kalman filter and cubic spline thus allow for variation in the NAIRU beyond that predicted by changing demographics. (The contribution of changing demography to the NAIRU is shown in figure 3.)

According to the Kalman filter estimates, the NAIRU starts to decline in the late 1980s and falls gradually throughout the 1990s. The rate of decline diminishes in the most recent year or so, leaving the NAIRU at the end of 1998 in the range of 4.5 to 5.4 percent, values that in all cases are higher than those estimated by intercept shifts. In contrast, the spline estimates fall more rapidly this decade and end at values that in most cases are less than the intercept-shift values. These differences notwithstanding, all approaches point to a decline

\footnotetext{
${ }^{11}$ Stock and Watson (1998) derives the median unbiased estimator and provides a mapping for several tests of coefficient stability from the value of each statistic to the variance of the random walk process in the Kalman filter. Our variance estimates are based on the values of the exponential F statistic for constancy of the intercept.
} 
in the NAIRU in the 1990s that in almost every case is larger in magnitude than movements in the NAIRU at any earlier time in the period under consideration.

\subsection{Import prices}

A common belief is that low import prices have been a substantial restraint on domestic inflation in the late 1990s. Over the four years from 1995 to 1998, the measures of import price inflation we use have increased between 2 and 3 percentage points more slowly at an annual rate, on average, than have the consumption and product prices under examination. Given the estimated coefficients on the relative rate of increase of import prices (between .04 and .12), these declines reduce the average (static) inflation prediction only about a tenth of a percentage point in the PCE, PCEX, and GDP equations, and about two tenths of a percentage point in the NFB equation. However, because these effects are small relative to the mean residuals of these equations over the 1995-1998 period (from 0.4 to 0.7 percentage points), we conclude that import prices have made a modest, but not substantial, contribution to holding down domestic inflation. ${ }^{12}$

An alternative analysis of the contribution of import prices focuses not only on the declining relative price of imports but also on the possibility of an increase in the sensitivity of domestic prices to the price of imports. And, indeed, statistical tests reveal that constancy of import price coefficients is rejected at the 1 percent level for PCE, at the 5 percent level for GDP, and at the 10 percent level for NFB. Two observations suggest the strong probability that these results are spurious, however. One is that it is difficult to distinguish in the mid-1990s a shift in the intercept from a shift in the import price coefficients, because of a downward shift in the mean of the relative rate of import price inflation that occurred around that time. Conditional on there being an intercept shift, evidence for a shift in import price coefficients significantly weakens, and similarly, conditional on a shift in import price coefficients, evidence for a shift in intercepts significantly weakens.

\footnotetext{
${ }^{12}$ As noted earlier, computers and semiconductors are wholly excluded in the import price measure used in consumption price equations and largely excluded in the measure entering product price equations. Given rapid declines in the prices of computers and semiconductors and their relatively large share in imports, import prices inclusive of these goods fall about 3 percentage points more rapidly at an annual rate, on average, over the 1995-1998 period than do measures that exclude them. If the model selection procedure is run with the broader measure of import prices in the set of explanatory variables, we find that, compared with the Baseline- 98 results, import prices are included in the same four equations, but that in those equations recent errors are slightly smaller and the statistical significance of an intercept shift is modestly reduced.
} 
The second observation calling into question a primary role of a shift in import price coefficients is that, when such a shift is allowed, the coefficients increase to implausibly large values after the shift date. In the equations with significant shifts, import price coefficients rise from 0.03 to 0.31 (PCE), 0.01 to 0.20 (GDP), and 0.10 to 0.48 (NFB). Of these, only the PCE contains prices of imported goods directly, and its post-shift import price coefficient is three times larger than an estimate of the import share (.09) based on the 1998 ratio of imports excluding oil, computers, and semiconductors to GDP. While some additional influence of import prices is likely on the price of that part of domestic production which competes with goods from abroad, such an effect seems unlikely to explain the large magnitude of the PCE coefficient. A similar argument holds for the import price coefficients in the GDP and NFB equations, in which the estimated effect of import prices must be entirely from import competition.

\section{Inflation lag length and smoothing restrictions}

A natural question to ask is whether our conclusions about the stability of baseline inflation equations are sensitive to the use of long inflation lags and coefficient smoothing restrictions. Evidence about NAIRU uncertainty suggests that this may be the case. Standard errors of NAIRU estimates in the Baseline-98 equations, which range from 0.12 to 0.24 percentage points, are much smaller than those others have reported using equations with shorter lags on inflation. SSW (1997a, p. 196) state that "a typical estimate of the NAIRU in 1990 is 6.2 percent, with a 95 percent confidence interval for the NAIRU in 1990 being 5.1 percent to 7.7 percent." Their result implies a standard error for the NAIRU that is four times larger than our average estimate.

\subsection{Estimates without smoothing restrictions}

When our specification selection procedure is modified so that coefficient smoothing restrictions are not permitted (table 3), we estimate equations that are similar to those of SSW in that they have relatively short inflation lag lengths-from four to seven quarters. Point estimates of the NAIRU are little changed, but the standard errors are about twice as large as those in the Baseline-98 set of equations. The less precise NAIRU estimates are associated with the result that the stability of intercepts cannot be rejected at the 10 percent 
Table 3: No Smoothing Restrictions

\begin{tabular}{|c|c|c|c|c|c|c|}
\hline & CPI & PCE & CPIX & PCEX & GDP & NFB \\
\hline \multicolumn{7}{|l|}{ Equation Specification: $^{a}$} \\
\hline inflation lags ${ }^{p d l}$ degree & 4 & 4 & 5 & 5 & 4 & 7 \\
\hline unemployment rate & $\mathrm{x}$ & $\mathrm{x}$ & $\mathrm{x}$ & $\mathrm{x}$ & $\mathrm{x}$ & $\mathrm{x}$ \\
\hline food and energy price & $\mathrm{x}$ & $\mathrm{x}$ & & $\mathrm{x}$ & $\mathrm{x}$ & $\mathrm{x}$ \\
\hline import price & $\mathrm{X}$ & $\mathrm{x}$ & $\mathrm{X}$ & $\mathrm{x}$ & $\mathrm{x}$ & $\mathrm{X}$ \\
\hline NAIRU & 6.04 & 5.95 & 5.96 & 5.80 & 5.92 & 5.86 \\
\hline$\left(\right.$ std. err. $\left.{ }^{b}\right)$ & $(.34)$ & $(.38)$ & $(.27)$ & $(.48)$ & $(.31)$ & $(.26)$ \\
\hline \multicolumn{7}{|l|}{ Stability tests: ${ }^{c}$} \\
\hline all coefficients & - & - & - & - & - & $* *$ \\
\hline intercept only & - & - & - & - & - & $* *$ \\
\hline
\end{tabular}

${ }^{a}$ Coefficient estimates and regression statistics are presented in the appendix.

${ }^{b}$ One-half of the 70 percent confidence range.

${ }^{c}$ Significance level: $>.10(-), .10(*), .05(* *)$, or $.01(* * *)$.

significance level, except for NFB inflation for which a shift in the NAIRU appears likely, but occurring in the late 1950s. The paucity of evidence for an intercept shift in these equations is consistent with Stock and Watson (1999), who find that Phillips curves with up to eleven monthly lags on inflation and unemployment show little sign of instability jointly among the intercept and unemployment coefficients.

We use CPI equations to illustrate in more detail the strong negative relationship between the lag length on inflation and the standard error of the NAIRU. For this measure of inflation, the standard error of the NAIRU falls from 0.34 percentage points in the equation without smoothing restrictions and four lags of inflation to 0.12 percentage points in the Baseline-98 equation with twenty-four lags of inflation whose coefficients are restricted to lie on a second degree polynomial. Figure 4 demonstrates that the relationship between the maximum inflation lag and the standard error of the NAIRU is nearly monotonic as the maximum lag varies between three and twenty-seven, with the standard error falling steeply as the lag length initially increases and then declining very gradually beyond thirteen lags. The standard error of the NAIRU at twenty-four lags, where the Schwartz criterion is minimized, is not that much less than the standard error at thirteen lags. A similar pattern is found for the other measures of inflation: The precision of the NAIRU increases substantially as the inflation lag length rises from short to moderate values (8-12 lags) and then 
Figure 4

Precision of NAIRU Estimates (CPI)

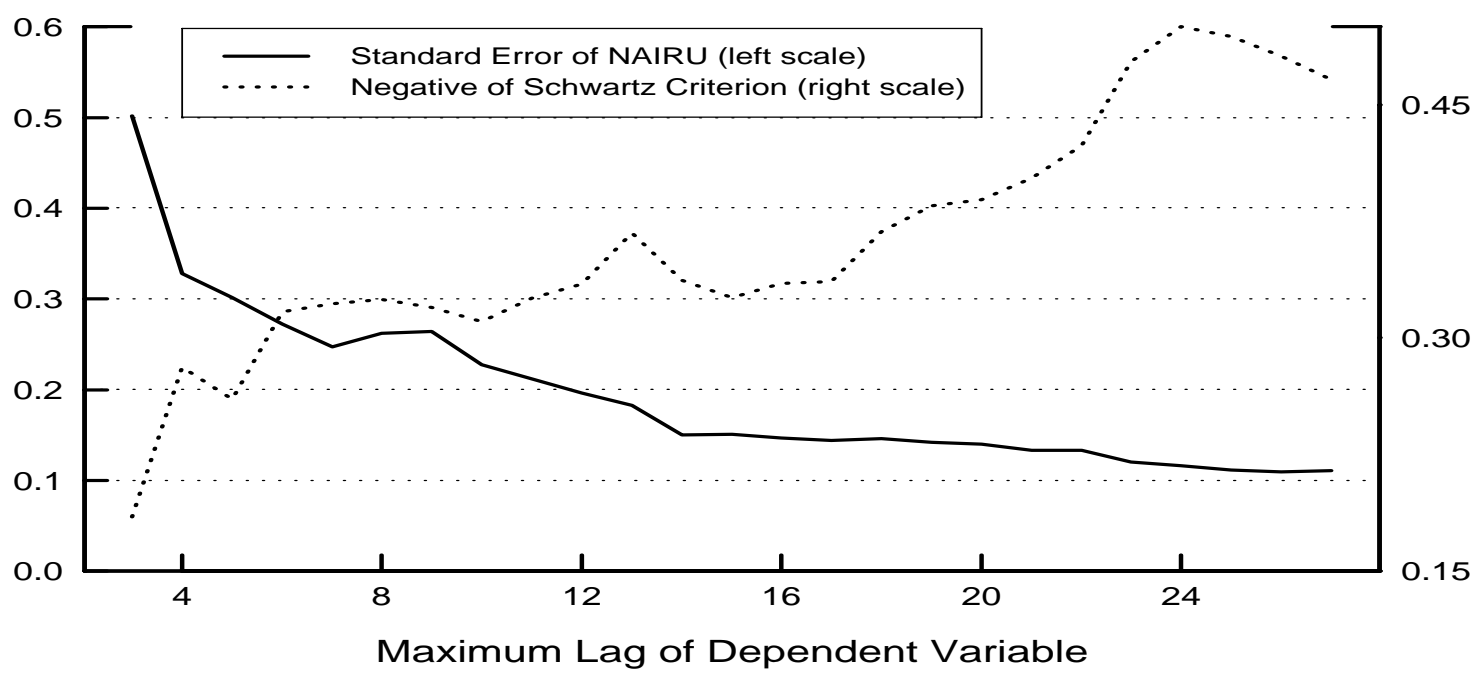

Note: Standard Error of NAIRU computed as one-half of $70 \%$ confidence interval

tends to flatten out as additional lags of past inflation are included.

\subsection{Out-of-sample forecasts}

Given the stark contrast in results depending on the inflation lag length and whether or not smoothing restrictions are imposed, we now compare the accuracy of the long-lag equations and the short-lag specifications in out-of-sample forecasts. Three variants of the selection procedure are used in this analysis. The first $(\max =25)$, which allows PDL smoothing restrictions and permits up to twenty-five inflation lags, is the approach used to derive the Baseline-89 and Baseline-98 sets of equations, except that now the selection procedure is run over a sequence of estimation periods whose terminal date advances one quarter at a time. The second alternative does not permit smoothing (no-pdl). The last case $(\max =12)$ shortens the feasible inflation lag length to twelve quarters while still permitting coefficient smoothing, an intermediate case which is motivated by the frequent use of twelve lags of inflation in estimated Phillips curves (e.g., Fuhrer (1995), Tootel (1994)).

The first out-of-sample forecast interval starts in 1975:Q1 based on models selected and estimated through 1974:Q4, except for PCEX whose initial forecast starts at 1977:Q1, 
Table 4: Out-of-Sample Forecast RMSEs

\begin{tabular}{|c|c|c|c|c|c|c|}
\hline \multicolumn{7}{|c|}{ (percent) } \\
\hline & CPI & $\mathrm{PCE}$ & CPIX & PCEX & GDP & NFB \\
\hline \multicolumn{7}{|c|}{ Four-Quarters-Ahead } \\
\hline maxlag $=25$ & .60 & .72 & 1.25 & .93 & .73 & 1.02 \\
\hline maxlag $=12$ & .77 & .74 & .76 & .76 & .76 & 1.04 \\
\hline no-pdl & .85 & .82 & 1.04 & .76 & .95 & 1.53 \\
\hline \multicolumn{7}{|c|}{ Eight-Quarters-Ahead } \\
\hline maxlag $=25$ & 1.23 & 1.45 & 2.63 & 2.04 & 1.42 & 1.86 \\
\hline maxlag $=12$ & 1.82 & 1.51 & 1.60 & 1.48 & 1.33 & 1.79 \\
\hline no-pdl & 2.14 & 1.78 & 2.77 & 1.68 & 2.24 & 3.42 \\
\hline
\end{tabular}

given the shorter historical time span over which data on this measure of inflation is available. For all inflation measures, the last forecast period ends at 1998:Q4. The results in table 4, which reports root mean squared percentage forecast errors for the price level at horizons of four and eight quarters, confirm the conclusion based on in-sample results that long-lag inflation equations tend to be superior to short-lag ones. In nine of twelve cases, our model selection procedure $(\max =25)$ yields price-level forecasts that have smaller root mean squared errors than does the procedure not permitting coefficient smoothing (no-pdl). In some cases, however, the intermediate procedure $(\max =12)$, in which smoothing restrictions are permissible but inflation lag lengths are constrained to be no more than twelve quarters, yields more accurate forecasts than does the longer-lag variant.

\subsection{Monte Carlo analysis}

In this section, we report four experiments with models of CPI inflation designed to address the question of whether model-selection criteria can discriminate between long-lag and short-lag models of the Phillips curve in samples such as the one we are examining. In the first two experiments, we repeatedly generate artificial data assuming that our long-lag, low-order model for own-lags in the Phillips curve is the correct model (table 2, column 1) and then run two different model-selection procedures, one of which allows for the possibility of polynomial smoothing restrictions, and the other of which does not. In the next pair of experiments, we generate sets of artificial data assuming the true model is such that inflation lags are short and unrestricted (table 3, column 1). We then run the two different model-selection exercises on each set of artificial data. 
Figure 5

\section{Model Selection Rules \\ Results from the Monte Carlo Exercise}
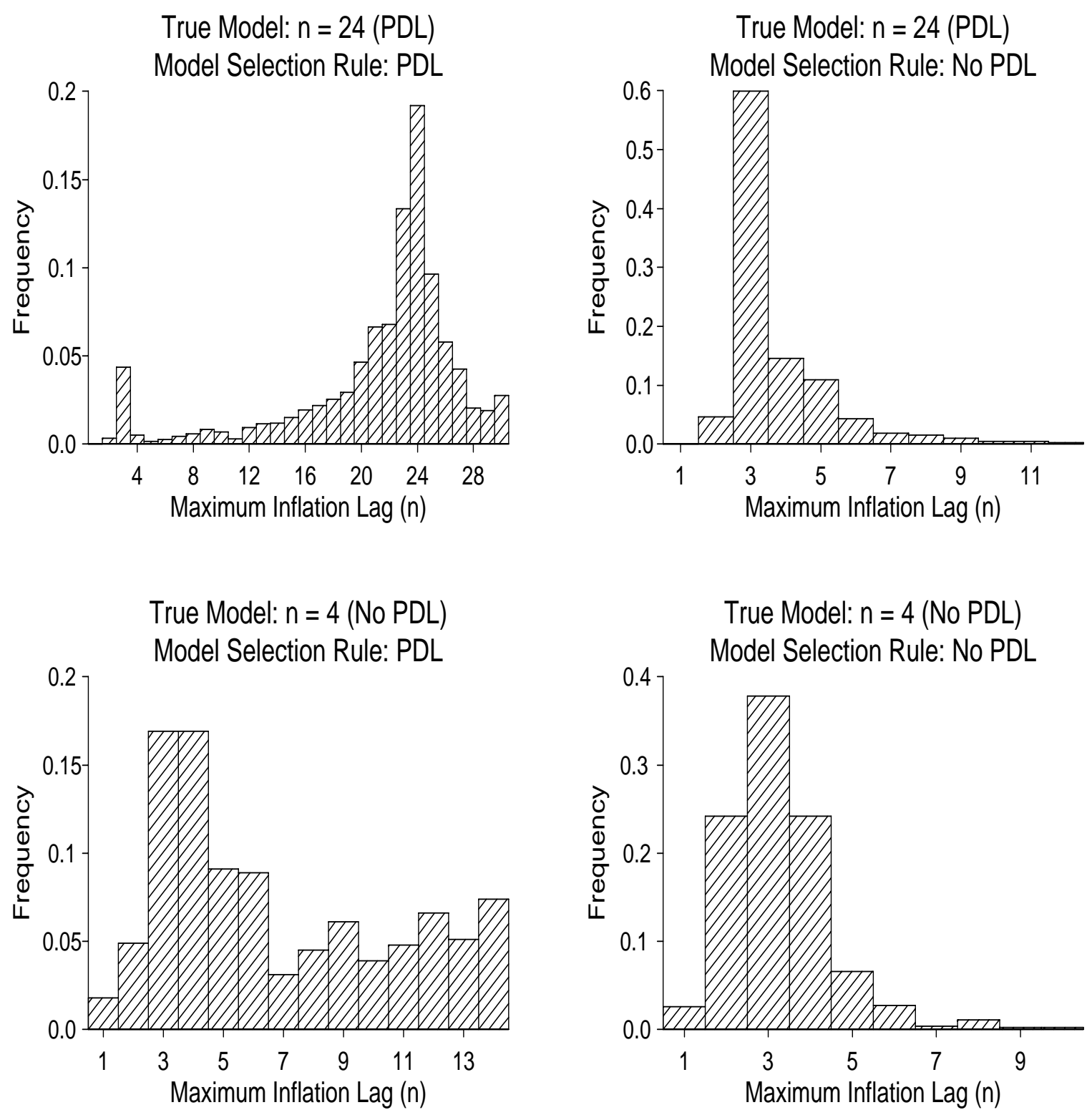
We use a six-lag VAR to generate simulated data for the other endogenous variables in the model, namely, the unemployment rate; the relative food-and-energy price; and relative import prices. We assume that the unemployment rate is unaffected in the current period by any of the other variables in the model; that relative food-and-energy prices are affected by the unemployment rate but not by any of the other variables; and that relative import prices are affected by unemployment and food-and-energy prices but not aggregate inflation.

Based on one thousand draws, we find that when the model used to generate the artificial data is the long-lags version of the Phillips curve, the specification-search procedure that allows for smoothing restrictions generally chooses long lags (figure 5, upper left panel), and that the search procedure which does not allow for smoothing restrictions selects a short-lag model (upper right panel). In particular, the median lag length when smoothing restrictions are allowed is twenty-three, compared to the true lag length of twenty-four (with the coefficients constrained to lie on a second-order polynomial). In 75 percent of the draws, the chosen lag length is twenty or more. In only 5 percent of the draws is the chosen lag length four or less. By contrast, when only unconstrained lags are allowed, the median lag length chosen is three, and in 99 percent of cases the chosen lag length is ten or less. When the true model involves low order and long lags, a model-specification procedure that does not allow for this possibility will choose a specification with far too few lags.

As noted previously, when we run the model-specification search for a model for the CPI allowing only for unconstrained own-lag specifications, the procedure chooses four lags. Using this specification to generate artificial data, the median number of lags chosen when the model search procedure is limited to consider only unconstrained lags is three (lower right panel), and in 95 percent of the cases, the number of lags is five or fewer. When reduced-order polynomials are allowed, the median number of lags selected is six while the ninety-fifth percentile of the distribution is fourteen lags (lower left panel).

On the whole, the more-general model-selection procedure that allows low-order polynomials out-performs the procedure that permits only unrestricted lags. The median lag estimated by the first method is close to the inflation lag length used to generate the artificial data in all experiments, while the median lag estimated by the second method is severely biased down when the true model has long lags. 
Table 5: Capacity Utilization Equations

\begin{tabular}{|lcccccc|}
\hline & CPI & PCE & CPIX & PCEX & GDP & NFB \\
\hline $\begin{array}{l}\text { Equation Specification: } \\
\text { inflation lags }\end{array}$ pdl degree & $24^{2}$ & $10^{4}$ & $9^{4}$ & $24^{2}$ & $19^{2}$ & $17^{2}$ \\
capacity utilization & $\mathrm{x}$ & $\mathrm{x}$ & $\mathrm{x}$ & $\mathrm{x}$ & $\mathrm{x}$ & $\mathrm{x}$ \\
food and energy price & $\mathrm{x}$ & $\mathrm{x}$ & $\mathrm{x}$ & $\mathrm{x}$ & $\mathrm{x}$ & $\mathrm{x}$ \\
$\quad$ import price & $\mathrm{x}$ & $\mathrm{x}$ & $\mathrm{x}$ & $\mathrm{x}$ & $\mathrm{x}$ & $\mathrm{x}$ \\
NAICU & 81.31 & 81.62 & 81.70 & 81.92 & 81.72 & 81.79 \\
$\quad\left(\right.$ std. err. $^{b}$ ) & $(.43)$ & $(.62)$ & $(.66)$ & $(.76)$ & $(.46)$ & $(.54)$ \\
Stability tests: & & & & & & \\
$\quad \begin{array}{l}\text { all coefficients } \\
\text { intercept only }\end{array}$ & $* * *$ & - & - & - & $*$ & - \\
\end{tabular}

${ }^{a}$ Coefficient estimates and regression statistics are presented in the appendix.

${ }^{b}$ One-half of the 70 percent confidence range.

${ }^{c}$ Significance level: $>.10(-), .10(*), .05(* *)$, or $.01(* * *)$.

\subsection{Summary of baseline equations}

Viewing the complete set of baseline equations, out-of-sample forecasts, and Monte Carlo analysis, the evidence favors the long-lag inflation equations in which the NAIRU is estimated precisely (but appears to have been unstable recently) over the short-lag equations with wide confidence bands and no evidence of instability. We next turn to the question of whether there are economic explanations other than a decline in the NAIRU for the recent low rates of inflation.

\section{Capacity Utilization}

Much has been made of late of the divergent signals about resource utilization coming from the labor and production markets in the late 1990s. Although utilization rates in the two typically move together fairly closely, labor utilization has been higher relative to its historical average than has capacity usage. Thus, the rate of capacity utilization seems more consistent with the recent inflation picture than does the unemployment rate. We use the Schwartz criterion to develop a set of equations that include capacity utilization in place of the unemployment rate. As reported in table 5, only the CPI and GDP equations show 
Table 6: Unemployment Rate (U) vs Capacity Utilization (CU): In Sample

\begin{tabular}{|c|c|c|c|c|}
\hline & \multicolumn{4}{|c|}{ t-statistic } \\
\hline & $\begin{array}{c}\text { Eq } \\
\mathrm{U}\end{array}$ & $\begin{array}{l}\text { ased on } \mathrm{U} \\
\mathrm{CU}\end{array}$ & $\begin{array}{c}\text { Eql } \\
\mathrm{U}\end{array}$ & $\begin{array}{l}\text { ased on } \mathrm{CU} \\
\mathrm{CU}\end{array}$ \\
\hline CPI & 5.0 & 0.9 & 4.3 & 1.1 \\
\hline PCE & 3.7 & 0.6 & 1.8 & 1.4 \\
\hline CPIX & 3.1 & 0.7 & 2.2 & 0.9 \\
\hline PCEX & 1.6 & 1.1 & 1.6 & 1.3 \\
\hline GDP & 2.4 & 1.8 & 2.3 & 2.1 \\
\hline NFB & 1.3 & 2.4 & 1.3 & 2.4 \\
\hline
\end{tabular}

significant evidence of coefficient instability when capacity utilization is the measure of demand pressure. And, the instability in these instances is associated with the early part of the estimation period, not the 1990s. The conclusion that inflation equations are more stable when they contain capacity utilization than when they contain the unemployment rate coincides with estimates presented by Gordon (1998) showing much less movement in the 1990s in a time-varying NAICU (Non-Accelerating Inflation rate of Capacity Utilization) than in a time-varying NAIRU.

Although capacity utilization has an edge in explaining recent inflation, that is not the case for the whole estimation period. We reestimated the unemployment rate equations with capacity utilization added as an explanatory variable while also reestimating the capacity utilization equations with the unemployment rate added. In terms of statistical significance, the unemployment rate dominates capacity utilization in all but the NFB equations-irrespective of whether the specification was initially tuned to contain the unemployment rate or capacity utilization (table 6).

A further comparison of unemployment and capacity utilization makes use of out-ofsample forecast errors (table 7). Based on forecasts of equations chosen by our preferred model selection procedure $(\max =25)$, the equations with the unemployment rate are more accurate at forecasting three measures of inflation, while equations with capacity utilization are more accurate at forecasting the other three inflation series. The outcome of this experiment is a draw.

All told, while conventional statistical testing suggests that the unemployment rate dominates capacity utilization in terms of in-sample fit, out-of-sample forecasting exer- 
Table 7: Unemployment Rate (U) vs Capacity Utilization (CU): Out of Sample RMSEs

\begin{tabular}{|lllllll|}
\hline & CPI & PCE & CPIX & PCEX & GDP & NFB \\
\hline \multicolumn{7}{l}{ Four-Quarters-Ahead } \\
U (maxlag=25) & $\mathbf{. 6 0}$ & $\mathbf{. 7 2}$ & 1.25 & .93 & $\mathbf{. 7 3}$ & 1.02 \\
CU (maxlag=25) & .65 & .77 & $\mathbf{. 9 4}$ & .77 & .84 & $\mathbf{1 . 0 0}$ \\
& Eight-Quarters-Ahead & & \\
U (maxlag=25) & $\mathbf{1 . 2 3}$ & $\mathbf{1 . 4 5}$ & 2.63 & 2.04 & $\mathbf{1 . 4 2}$ & 1.86 \\
CU (maxlag=25) & 1.37 & 1.69 & $\mathbf{1 . 7 9}$ & $\mathbf{1 . 5 4}$ & 1.77 & $\mathbf{1 . 8 3}$ \\
\hline
\end{tabular}

cises suggest that neither measure is superior. This result is perhaps less surprising once it is recalled that by construction the out-of-sample analysis puts greater weight on the recent experience.

\section{The Markup}

Thus far, the Phillips curves we have examined have clearly been reduced-form relationships. A more structural perspective might view prices as a function of costs. To pursue this approach, we add the the markup of prices in the nonfarm business sector over trend unit labor costs-where the latter is compensation per hour from the BLS Productivity and Cost release, relative to a measure of the trend in productivity that allows a single break in its slope in 1973 - as a potential determinant of price inflation. As shown by the solid line in figure 6, the markup over trend unit labor costs has no discernable trend historically and has been relatively high over much of the past five years - the period of "unusually" low inflation. ${ }^{13}$

Our analysis starts with the specification selection procedure used earlier, but with the set of potential explanatory variables augmented to include the first lag of the log of the markup over trend unit labor costs-which we will refer to as the "trend markup." In an earlier stage of our research, the lagged level as well as several lagged growth rates of the trend markup were part of the set of potential regressors, but the growth rates were never selected for inclusion in the final equations. Note that the nonfarm trend markup is used in equations for all six measures of inflation. One reason for not having markup variables

\footnotetext{
${ }^{13}$ If the Employment Cost Index measure of hourly compensation, which begins in 1980, is spliced with the Productivity and Cost series, a similar pattern is found. In addition, the statistical conclusions presented below are unaffected if the spliced series is used.
} 
Figure 6

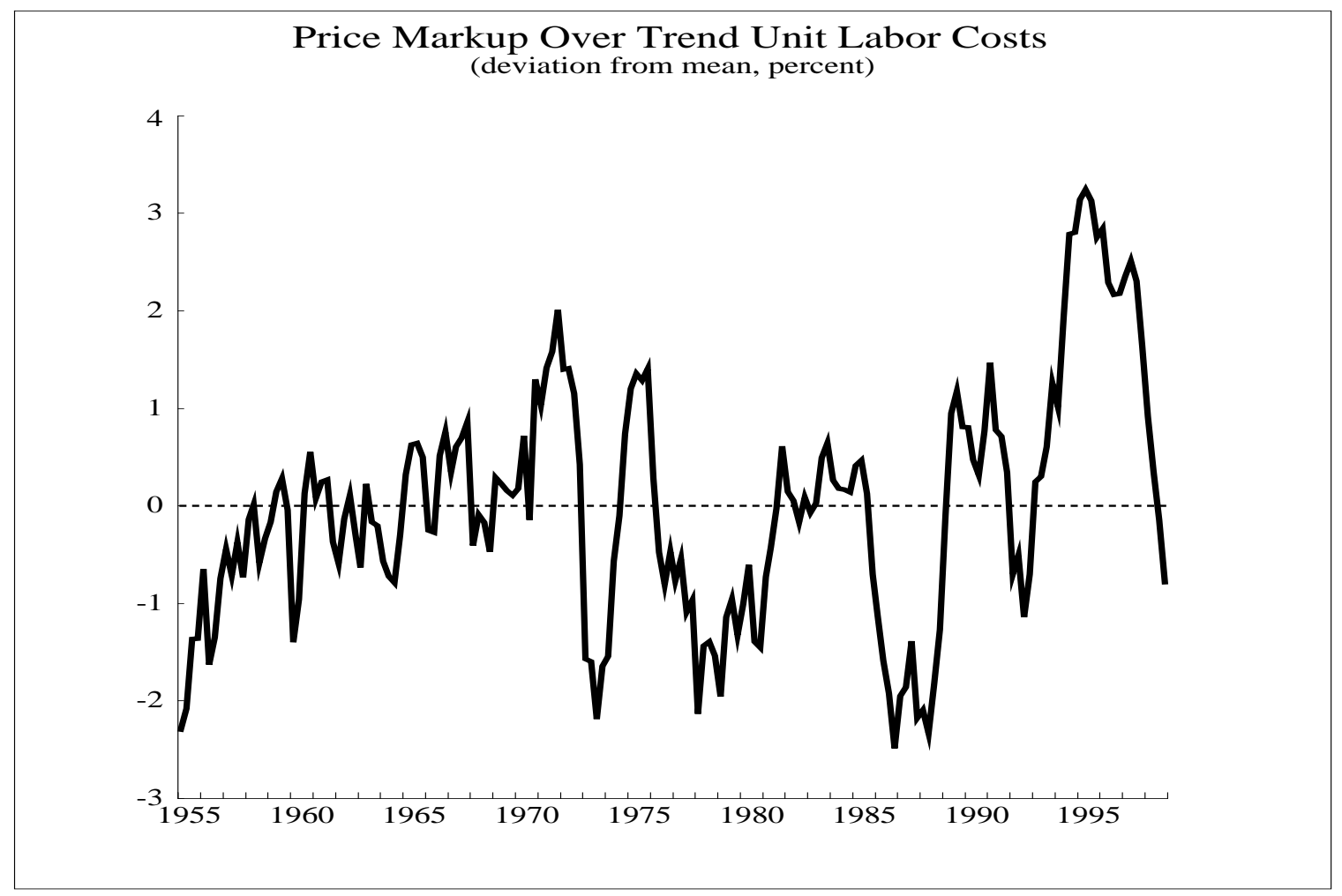

that are specific to each inflation series is the difficultly in constructing consistently defined markups for consumption and GDP. Even without this practical consideration, however, the fact that the nonfarm markup is a broad measure of labor cost pressure on the price of domestic production makes it a plausible determinant of each inflation series. The unemployment rate is the measure of slack included in the set of explanatory variables.

According to the selection criterion, the lagged level of the trend markup appears in all inflation equations, as shown in table 8. This variable has the implication that, when the price level is high relative to trend unit labor costs, downward pressure is exerted on all the measures of inflation investigated. Given the relatively high level of the markup over much of this decade, residuals of all equations containing the labor cost measure are small until very recently, and only the PCEX equation shows significant evidence of intercept instability. However, the most likely date for a shift of the intercept in this instance is during 1978, not in the 1990s.

Because the compensation component of the markup varies with the unemployment 
Table 8: Markup Equations

\begin{tabular}{|c|c|c|c|c|c|c|}
\hline & $\mathrm{CPI}$ & PCE & CPIX & PCEX & GDP & NFB \\
\hline $\begin{array}{l}\text { Equation Specification: }^{a} \\
\text { inflation lags }\end{array}$ & $24^{3}$ & $24^{2}$ & $23^{2}$ & $24^{2}$ & $15^{2}$ & $17^{2}$ \\
\hline unemployment rate & $\mathrm{x}$ & $\mathrm{x}$ & $\mathrm{x}$ & $\mathrm{x}$ & $\mathrm{x}$ & $\mathrm{x}$ \\
\hline food and energy price & $\mathrm{x}$ & $\mathrm{x}$ & $\mathrm{x}$ & $\mathrm{x}$ & $\mathrm{x}$ & $\mathrm{x}$ \\
\hline import price & & $\mathrm{x}$ & & & $\mathrm{x}$ & $\mathrm{x}$ \\
\hline trend markup & $\mathrm{x}$ & $\mathrm{X}$ & $\mathrm{X}$ & $\mathrm{x}$ & $\mathrm{x}$ & $\mathrm{x}$ \\
\hline $\begin{array}{l}\text { NAIRU }^{b} \\
\quad\left(\text { std. err. }^{c}\right)\end{array}$ & $\begin{array}{l}5.97 \\
(.10)\end{array}$ & $\begin{array}{l}5.88 \\
(.13)\end{array}$ & $\begin{array}{l}6.05 \\
(.16)\end{array}$ & $\begin{array}{l}6.01 \\
(.18)\end{array}$ & $\begin{array}{l}5.88 \\
(.15)\end{array}$ & $\begin{array}{l}5.84 \\
(.18)\end{array}$ \\
\hline \multicolumn{7}{|l|}{ Stability tests: ${ }^{d}$} \\
\hline all coefficients & - & - & - & - & - & - \\
\hline intercept only & - & - & - & * & - & - \\
\hline
\end{tabular}

${ }^{a}$ Coefficient estimates and regression statistics are presented in the appendix.

${ }^{b}$ Measured assuming the markup is at its sample mean.

${ }^{c}$ One-half of the 70 percent confidence range.

${ }^{d}$ Significance level: $>.10(-), .10(*), .05(* *)$, or $.01(* * *)$.

rate, the NAIRU is not uniquely defined by the structure of equations for price inflation when they contain the markup. Rather, such equations only pin down a linear relationship between the NAIRU and the equilibrium value of the markup. Nonetheless, for illustrative purposes, we report estimates of the NAIRU based on setting the markup to its sample mean. As is shown in table 8 , these estimates are close to 6 percent and are very similar to the NAIRU values in the Baseline-98 equations.

The improvement in coefficient stability that characterizes the markup equations is highlighted in figure 7, which contrasts Kalman filter estimates of time-varying NAIRUs for the markup specifications with those shown earlier for the Baseline-98 equations. ${ }^{14}$ Indeed, for the CPIX markup equation, the median unbiased estimate of the variance of innovations to the intercept is zero and its time-varying NAIRU is constant. And NAIRUs in the CPI, PCE, GDP and NFB equations with the markup fall only 0.12 to 0.21 percentage points from 1989 to 1998. Only the PCEX equations exhibit similar movements of the NAIRU over time in the markup and Baseline-98 specifications.

\footnotetext{
${ }^{14}$ The characteristics of figure 7 would be unchanged if estimates of time-varying intercepts were shown rather than time-varying NAIRUs.
} 
Figure 7

\section{Time-Varying NAIRUs}

CPI
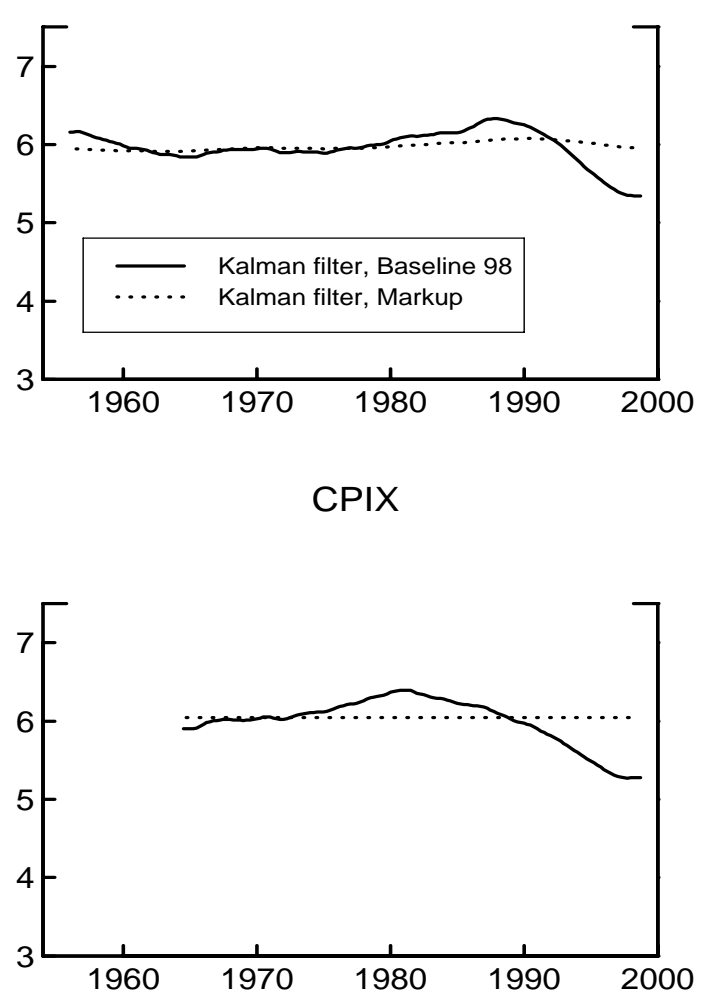

GDP

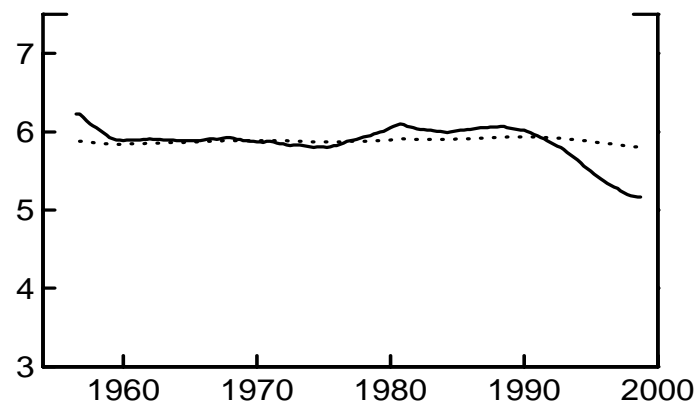

PCE
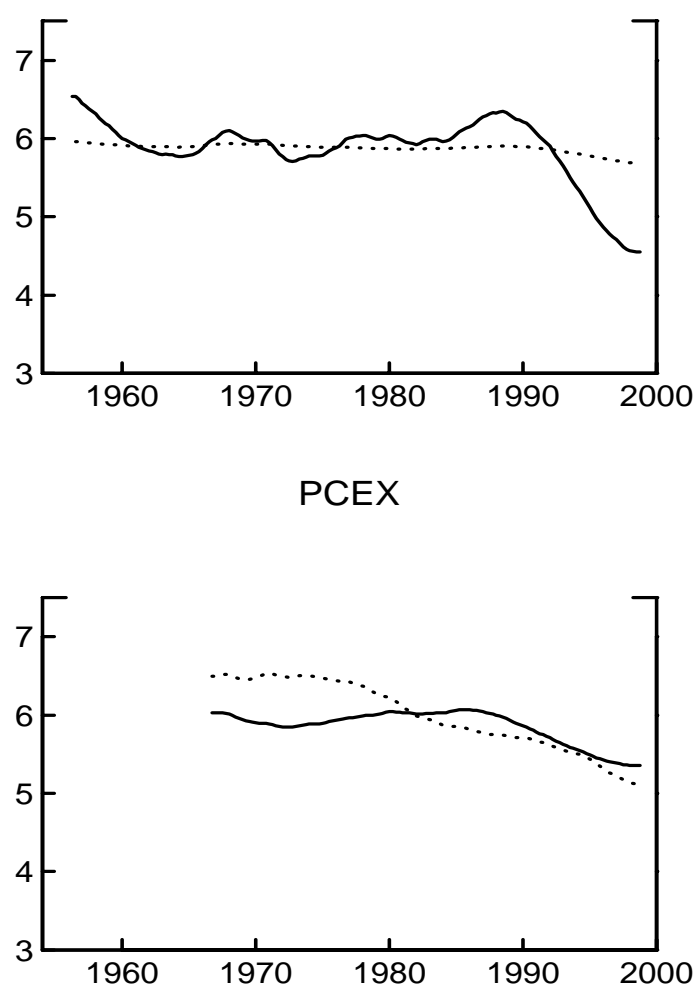

NFB

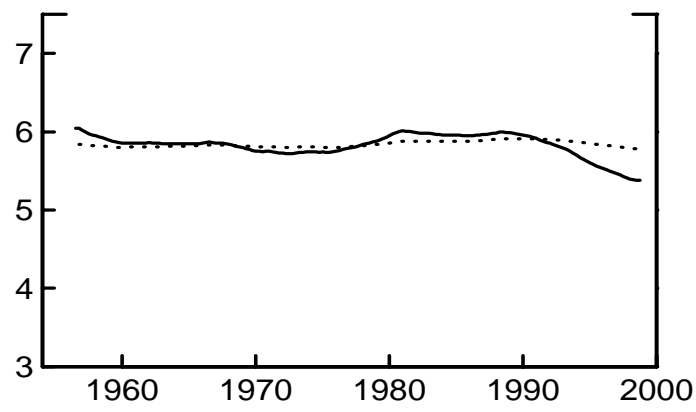


Figure 8

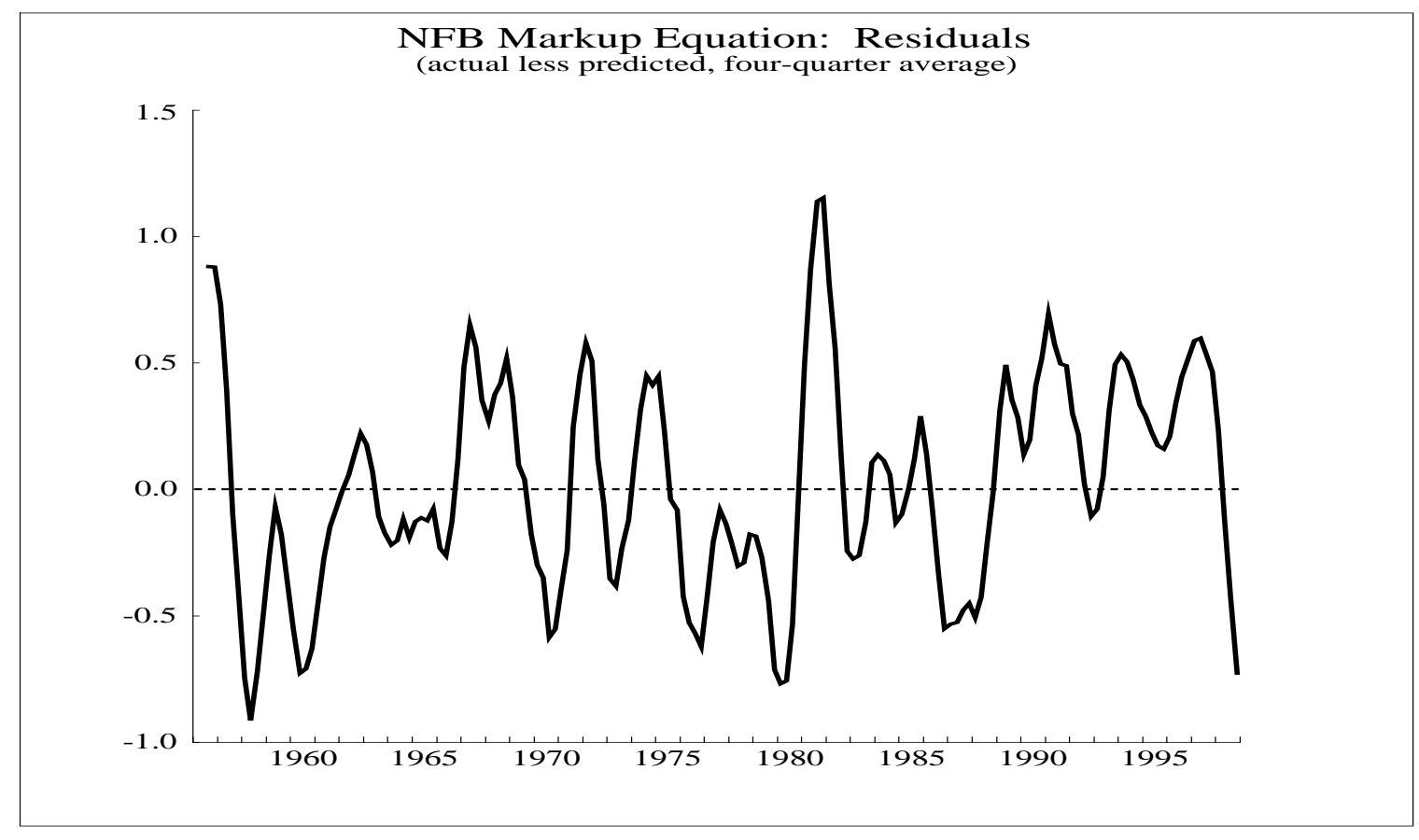

The case for the markup is bolstered by the finding that our results are not dependent on having the decade of the 1990s in the sample: The selection procedure includes the markup variable in all inflation equations when they are estimated through 1989. Hence, our hypothetical 1989 analyst would have included the markup as well.

The markup story is not without caveats, however. First, the results are sensitive to the particular measure of productivity entering the markup calculation. Although our main results go through when the trend is estimated with the HP filter, the markup variable is generally insignificant when actual productivity is used. Also, we do not have a clear story for the rise of the markup in the early 1990s. The residuals of the markup equation for NFB inflation are generally positive during this period (figure 8), suggesting that some of the rise in the markup may have been a result of unexplained price increases. Low rates of increase of hourly compensation in the first half of this decade may also have contributed, but an analysis of compensation developments is beyond the scope of this paper. Finally, as shown in figure 6, the markup has recently fallen back to a "normal" level and thus has not been much of a restraint on predicted inflation over the past year or so-a period in which the markup equations overpredict inflation by a substantial (but not unprecedented) 
amount (figure 8). Because the overprediction episode is as yet fairly short, it is too soon to say whether the errors are transitory or evidence of some other factor restraining inflation.

One possible restraint on recent inflation not captured in our markup equations would be a pickup in the trend rate of growth of labor productivity. If this were the case, the level of the trend markup might be higher than our measure, reducing the predicted rate of inflation. Much speculation has arisen concerning possible effects of booming investment in computers and related equipment on labor productivity, but as yet no consensus has emerged. And in one study pointing to an increase in the trend rate of growth of labor productivity in the nonfarm sector, the level of the trend is only slightly above our measure — based on the single kink at 1973 - at the end of 1998, and thus would not have substantially different implications for inflation. ${ }^{15}$

\section{Conclusions}

The baseline version of the Phillips curve cannot adequately explain why inflation has been so low in the second half of the 1990s. While import prices, which are part of the baseline specification, are estimated in most equations to have restrained inflation over the past few years, a full attribution of inflation developments to these prices would require a many-fold increase in their coefficients. Looking beyond the baseline framework, capacity utilization predicts inflation in the recent period more accurately than does the unemployment rate, but the reverse tends to hold for the estimation sample as a whole on an in-sample basis. Outof-sample forecast accuracy provides no basis for discriminating between the two measures of utilization.

We find that evidence favors a view in which price developments are, in part, determined by an "error-correction" mechanism involving the markup of prices over trend unit labor costs. A high markup puts downward pressure on price inflation and the reverse obtains when the markup is low. With markups relatively high through much of the 1990s, the error-correction channel is estimated to have held down inflation over much of this period. The reason for the past rise in the markup is somewhat unclear. However, markup levels at the end of 1998 are close to their historical averages and thus should not restrain inflation in the near future, unless, for some reason, firms are under pressure to reduce margins below

\footnotetext{
${ }^{15}$ Gordon (1999). We adjust Gordon's estimate of trend productivity growth to be consistent with our assumption about the effect of changes in price measurement methods on labor productivity.
} 
historical norms or trend labor productivity is rising faster than our simple calculation.

Additional support for the markup story comes from the observation that not only does it have a long history as a theoretical model of price determination but also that we find it empirically to be a stable part of inflation dynamics over time. The markup is an explanation of what has happened to inflation this decade that could have been identified as part of the inflation process prior to this decade. 


\section{References}

Andrews, Donald, Inpyo Lee, and Werner Ploberger (1996) Optimal Changepoint Tests for Normal Linear Regression. Journal of Econometrics, 70, 9-38.

Andrews, Donald, and Werner Ploberger (1994) Optimal Tests When a Nuisance Parameter is Present Only Under the Alternative. Econometrica, 62, 1383-1414.

Council of Economic Advisors (1999) Economic Report of the President. Washington D.C.: United States Government Printing Office.

Fuhrer, Jeffrey C. (1995) The Phillips Curve is Alive and Well. New England Economic Review of the Federal Reserve Bank of Boston, March/April, 41-56.

Gordon, Robert J. (1997) The Time-Varying NAIRU and its Implications for Economic Policy. Journal of Economic Perspectives, 11, 11-32.

Gordon, Robert J. (1998) Foundations of the Goldilocks Economy: Supply Shocks and the Time-Varying NAIRU. Brookings Papers on Economic Activity, 297-333.

Gordon, Robert J. (1999) Has the 'New Economy' Rendered the Productivity Slowdown Obsolete? Northwestern University, mimeo.

Katz, Lawrence F., and Alan B. Krueger (1999) The High-Pressure U.S. Labor Market of the 1990s. Brookings Papers on Economic Activity, forthcoming.

McIntire, Robert J. (1996) Revisions in Household Survey Data Effective February 1996. Employment and Earnings, March, 8-16.

Polivka, Anne E., and Stephen M. Miller (1995) The CPS After the Redesign: Refocusing the Economic Lens. Bureau of Labor Statistics, Mimeo, March. 
Staiger, Douglas, James H. Stock, and Mark W. Watson (1997a) How Precise Are Estimates of the Natural Rate of Unemployment? Reducing Inflation: Motivation and Strategy, ed. Christina D. Romer and David H. Romer. University of Chicago Press.

Staiger, Douglas, James H. Stock, and Mark W. Watson (1997b) The NAIRU, Unemployment and Monetary Policy Journal of Economic Perspectives, 11, 33-49.

Stock, James H., and Mark W. Watson (1998) Median Unbiased Estimation of Coefficient Variance in a Time-Varying Parameter Model. Journal of the American Statistical Association, 93, 349-58.

Stock, James H., and Mark W. Watson (1999) Forecasting Inflation. NBER working paper 7023.

Tootell, Geoffrey (1994) Restructuring, the NAIRU, and the Phillips Curve. New England Economic Review of the Federal Reserve Bank of Boston, September/October, 31-44. 


\section{Appendix Tables}

Table A1

Baseline-89 Equations

\begin{tabular}{|c|c|c|c|c|c|c|}
\hline & $\mathrm{CPI}$ & PCE & CPIX & PCEX & GDP & NFB \\
\hline $\begin{array}{l}\text { Estimated coefficients: }^{a} \\
\text { inflation lags }\end{array}$ & $\begin{array}{l}1.00_{1,25}^{2} \\
\quad(0.5)\end{array}$ & $\begin{array}{l}1.00{ }_{1,24}^{2} \\
(0.1)\end{array}$ & $\begin{array}{c}1.00_{1,24}^{2} \\
(1.9)\end{array}$ & $\begin{array}{l}1.00{ }_{1,24}^{2} \\
(0.1)\end{array}$ & $\begin{array}{l}1.00_{1,19}^{2} \\
(0.9)\end{array}$ & $\begin{array}{l}1.00{ }_{1,17}^{2} \\
\quad(0.1)\end{array}$ \\
\hline unemployment rate & $\begin{array}{c}-.54 \\
(11.7)\end{array}$ & $\begin{array}{l}-.45_{0,1}^{0} \\
(8.9)\end{array}$ & $\begin{array}{l}-.37 \\
(7.5)\end{array}$ & $\begin{array}{l}-.36_{0,3}^{0} \\
(6.2)\end{array}$ & $\begin{array}{l}-.477_{0,1}^{0} \\
(8.0)\end{array}$ & $\begin{array}{c}-.48{ }_{0,1}^{0} \\
(7.0)\end{array}$ \\
\hline $\begin{array}{l}\text { food and energy price } \\
\text { (contemporaneous) }\end{array}$ & $\begin{array}{c}.89 \\
(21.4)\end{array}$ & $\begin{array}{c}.94 \\
(15.2)\end{array}$ & & & $\begin{array}{c}.50 \\
(6.1)\end{array}$ & $\begin{array}{c}.57 \\
(6.3)\end{array}$ \\
\hline $\begin{array}{l}\text { food and energy price } \\
\text { (lags) }\end{array}$ & & & $\begin{array}{l}.45_{1,4}^{0} \\
\left(7.5^{)}\right.\end{array}$ & $\begin{array}{l}.50_{1,3}^{0} \\
(5.7)\end{array}$ & $\begin{array}{l}-.211,1 \\
(2.6)\end{array}$ & \\
\hline farm price & & & & & & $\begin{array}{c}-.02 \\
(8.1)\end{array}$ \\
\hline import price & & $\begin{array}{c}.03 \\
(2.8) \\
\end{array}$ & & & $\begin{array}{l}.07{ }_{0,3}^{0} \\
(4.5) \\
\end{array}$ & $\begin{array}{l}.11_{0,3}^{0} \\
(5.9) \\
\end{array}$ \\
\hline $\begin{array}{l}\text { Equation statistics: } \\
\text { sample period }\end{array}$ & $55.1-89.4$ & $55.1-89.4$ & $63.3-89.4$ & $65.3-89.4$ & $55.1-89.4$ & $55.1-89.4$ \\
\hline $\bar{R}^{2}$ & .9410 & .9320 & .8903 & .8565 & .9042 & .8934 \\
\hline SSR & 74.48 & 73.37 & 57.12 & 56.44 & 92.14 & 137.53 \\
\hline regression se & .7455 & .7427 & .7557 & .7832 & .8355 & 1.0207 \\
\hline Durbin-Watson & 1.81 & 1.61 & 1.80 & 1.52 & 1.83 & 1.84 \\
\hline
\end{tabular}

${ }^{a}$ For each regressor, the estimated coefficient, or coefficient sum, and t-statistic are reported. Entries that are coefficient sums are indicated by subscripts indexing the minimum and maximum lags, and, if polynomial restrictions are imposed, by a superscript reporting the polynomial degree. Equations also include an intercept and wage-price dummy.

${ }^{b}$ The reported t-statistic is associated with the deviation from one of the sum of coefficients on lagged inflation when it is not restricted. 
Table A2

Baseline-98 Equations

\begin{tabular}{|c|c|c|c|c|c|c|}
\hline & CPI & $\overline{\mathrm{PCE}}$ & CPIX & PCEX & GDP & NFB \\
\hline $\begin{array}{l}\text { Estimated coefficients: }^{a} \\
\quad \text { inflation lags }\end{array}$ & $\begin{array}{l}1.00{ }_{1,24}^{2} \\
(0.1)\end{array}$ & $\begin{array}{c}1.00_{1,24}^{2} \\
(0.2)\end{array}$ & $\begin{array}{c}1.00{ }_{1,23}^{2} \\
(2.3)\end{array}$ & $\begin{array}{l}1.00_{1,24}^{2} \\
\left(0.2^{2}\right)\end{array}$ & $\begin{array}{l}1.00{ }_{1,15}^{2} \\
(0.0)\end{array}$ & $\begin{array}{l}1.00{ }_{1,17}^{2} \\
(0.2)\end{array}$ \\
\hline unemployment rate & $\begin{array}{l}-.50{ }_{0,1}^{0} \\
(11.3)\end{array}$ & $\begin{array}{l}-.40_{0,1}^{0} \\
(8.3)\end{array}$ & $\begin{array}{l}-.35 \\
(8.0)\end{array}$ & $\begin{array}{l}-.27{ }_{0,3}^{0} \\
(5.0)\end{array}$ & $\begin{array}{l}-.37 \\
(6.8)\end{array}$ & $\begin{array}{l}-.41 \stackrel{0}{0}, 1 \\
(6.3)\end{array}$ \\
\hline $\begin{array}{l}\text { food and energy price } \\
\text { (contemporaneous) }\end{array}$ & $\begin{array}{c}.89 \\
(23.1)\end{array}$ & $\begin{array}{c}.90 \\
(15.0)\end{array}$ & & & $\begin{array}{c}.38 \\
(5.6)\end{array}$ & $\begin{array}{c}.54 \\
(6.6)\end{array}$ \\
\hline $\begin{array}{l}\text { food and energy price } \\
\text { (lags) }\end{array}$ & & & $\begin{array}{l}.45_{1,4}^{0} \\
(8.2)\end{array}$ & $\begin{array}{l}.36_{1,3}^{0} \\
(3.8)\end{array}$ & & \\
\hline farm price & & & & & & $\begin{array}{l}-.02 \\
(8.5)\end{array}$ \\
\hline import price & & $\begin{array}{l}.04{ }_{0,1}^{0} \\
(3.8)\end{array}$ & & $\begin{array}{l}.04{ }_{0,1}^{0} \\
(3.3)\end{array}$ & $\begin{array}{l}.05_{0,1}^{1} \\
(3.8)\end{array}$ & $\begin{array}{l}.11_{0,2}^{0} \\
(6.9)\end{array}$ \\
\hline \multicolumn{7}{|l|}{ Equation statistics: } \\
\hline sample period & $55.1-98.4$ & $55.1-98.4$ & $63.3-98.4$ & $65.3-98.4$ & $55.1-98.4$ & $55.1-98.4$ \\
\hline $\bar{R}^{2}$ & .9350 & .9223 & .8909 & .8796 & .8962 & .8845 \\
\hline SSR & 89.48 & 94.48 & 68.80 & 71.51 & 114.73 & 166.58 \\
\hline regression se & .7255 & .7477 & .7112 & .7504 & .8264 & .9958 \\
\hline Durbin-Watson & 1.66 & 1.51 & 1.74 & 1.53 & 1.76 & 1.74 \\
\hline
\end{tabular}

${ }^{a}$ For each regressor, the estimated coefficient, or coefficient sum, and t-statistic are reported. Entries that are coefficient sums are indicated by subscripts indexing the minimum and maximum lags, and, if polynomial restrictions are imposed, by a superscript reporting the polynomial degree. Equations also include an intercept and wage-price dummy.

${ }^{b}$ The reported t-statistic is associated with the deviation from one of the sum of coefficients on lagged inflation when it is not restricted. 
Table A3

No Smoothing Restrictions

\begin{tabular}{|c|c|c|c|c|c|c|}
\hline & CPI & PCE & CPIX & PCEX & GDP & NFB \\
\hline $\begin{array}{l}\text { Estimated coefficients: }^{a} \\
\text { inflation lags }{ }^{b}\end{array}$ & $\begin{array}{c}1.00_{1,4}^{3} \\
(1.2)\end{array}$ & $\begin{array}{c}1.00{ }_{1,4}^{3} \\
(1.7)\end{array}$ & $\begin{array}{c}1.00_{1,5}^{4} \\
(0.6)\end{array}$ & $\begin{array}{c}1.00_{1,5}^{4} \\
(1.0)\end{array}$ & $\begin{array}{c}1.00{ }_{1,4}^{3} \\
(2.8)\end{array}$ & $\begin{array}{c}1.00{ }_{1,7}^{6} \\
(3.0)\end{array}$ \\
\hline unemployment rate & $\begin{array}{l}-.19_{0,2}^{2} \\
(3.8)\end{array}$ & $\begin{array}{l}-.17 \\
(3.5)\end{array}$ & $\begin{array}{l}-.24 \\
(4.9)\end{array}$ & $\begin{array}{l}-.15 \\
(3.0)\end{array}$ & $\begin{array}{l}-.23 \\
(4.2)\end{array}$ & $\begin{array}{l}-.32 \\
(4.7)\end{array}$ \\
\hline $\begin{array}{l}\text { food and energy price } \\
\text { (contemporaneous) }\end{array}$ & $\begin{array}{c}.88 \\
(17.4)\end{array}$ & $\begin{array}{c}.95 \\
(13.2)\end{array}$ & & & $\begin{array}{c}.34 \\
(4.5)\end{array}$ & $\begin{array}{c}.47 \\
(5.3)\end{array}$ \\
\hline $\begin{array}{l}\text { food and energy price } \\
\text { (lags) }\end{array}$ & $\begin{array}{l}-.69_{1,4}^{3} \\
(10.1)\end{array}$ & $\begin{array}{l}-.81_{1,4}^{3} \\
(8.2)\end{array}$ & & $\begin{array}{l}.17_{1,1} \\
(2.5)\end{array}$ & $\begin{array}{l}-.251,1 \\
(3.3)\end{array}$ & \\
\hline farm price & & & & & & $\begin{array}{l}-.02 \\
(7.3)\end{array}$ \\
\hline import price & $\begin{array}{c}.04 \\
(3.4)\end{array}$ & $\begin{array}{c}.05 \\
(4.7)\end{array}$ & $\begin{array}{c}.05 \\
(5.3)\end{array}$ & $\begin{array}{c}.04 \\
(4.2)\end{array}$ & $\begin{array}{l}.07{ }_{0,1}^{1} \\
(5.0)\end{array}$ & $\begin{array}{l}.122 \\
(6.3)\end{array}$ \\
\hline Equation statistics: & $551 \quad 004$ & 551 oe & 632084 & 653094 & 551 oe & $551 \quad 084$ \\
\hline $\bar{R}^{2}$ & $\begin{array}{c}\text { JJ.1 - } 90.4 \\
.9273\end{array}$ & $\begin{array}{c}\text { JJ.1 - } 90.4 \\
.9154\end{array}$ & $\begin{array}{c}03.3-90.4 \\
.8755\end{array}$ & $\begin{array}{c}0.3-90.4 \\
.8785\end{array}$ & $\begin{array}{c}\text { J. } 1-90.4 \\
.8844\end{array}$ & $\begin{array}{c}\text { J5. }-90.4 \\
.8674\end{array}$ \\
\hline SSR & 95.40 & 99.83 & 77.37 & 71.00 & 126.31 & 184.49 \\
\hline regression se & .7674 & .7802 & .7599 & .7536 & .8723 & 1.0672 \\
\hline Durbin-Watson & 2.02 & 2.04 & 2.03 & 2.01 & 2.02 & 1.74 \\
\hline
\end{tabular}

${ }^{a}$ For each regressor, the estimated coefficient, or coefficient sum, and t-statistic are reported. Entries that are coefficient sums are indicated by subscripts indexing the minimum and maximum lags, and, if polynomial restrictions are imposed, by a superscript reporting the polynomial degree. Equations also include an intercept and wage-price dummy.

${ }^{b}$ The reported t-statistic is associated with the deviation from one of the sum of coefficients on lagged inflation when it is not restricted. 
Table A4

Capacity Utilization Equations

\begin{tabular}{|c|c|c|c|c|c|c|}
\hline & $\mathrm{CPI}$ & PCE & CPIX & PCEX & GDP & NFB \\
\hline $\begin{array}{l}\text { Estimated coefficients: }^{a} \\
\text { inflation lags }\end{array}$ & $\begin{array}{c}1.00{ }_{1,24}^{2} \\
(1.8)\end{array}$ & $\begin{array}{l}1.00_{1,10}^{4} \\
(2.4)\end{array}$ & $\begin{array}{c}1.00_{1,9}^{4} \\
(0.0)\end{array}$ & $\begin{array}{c}1.00_{1,24}^{2} \\
(0.1)\end{array}$ & $\begin{array}{c}1.00{ }_{1,19}^{2} \\
(0.8)\end{array}$ & $\begin{array}{l}1.00_{1,17}^{2} \\
(0.8)\end{array}$ \\
\hline capacity utilization & $\begin{array}{l}.14_{0,1}^{0} \\
(9.1)\end{array}$ & $\begin{array}{l}.099_{0,3}^{0} \\
(5.0)\end{array}$ & $\begin{array}{l}.09_{0,3}^{0} \\
(5.4)\end{array}$ & $\begin{array}{l}.09_{0,3}^{0} \\
(5.2)\end{array}$ & $\begin{array}{l}.14_{0,3}^{0} \\
(7.2)\end{array}$ & $\begin{array}{l}.15_{0,3}^{0} \\
(6.7)\end{array}$ \\
\hline $\begin{array}{l}\text { food and energy price } \\
\text { (contemporaneous) }\end{array}$ & $\begin{array}{c}.89 \\
(19.4)\end{array}$ & $\begin{array}{c}.87 \\
(13.3)\end{array}$ & & & $\begin{array}{c}.35 \\
(5.1)\end{array}$ & $\begin{array}{c}.49 \\
(5.9)\end{array}$ \\
\hline $\begin{array}{l}\text { food and energy price } \\
\text { (lags) }\end{array}$ & $\begin{array}{l}-.24{ }_{1,4}^{0} \\
(3.2)\end{array}$ & $\begin{array}{l}-.381,1 \\
(4.8)\end{array}$ & $\begin{array}{l}.28_{1,4}^{0} \\
(4.0)\end{array}$ & $\begin{array}{l}.36_{1,4}^{0} \\
(3.7)\end{array}$ & & \\
\hline farm price & & & & & & $\begin{array}{c}-.02 \\
(8.7)\end{array}$ \\
\hline import price & $\begin{array}{c}.03 \\
(2.6) \\
\end{array}$ & $\begin{array}{c}.04 \\
(3.9) \\
\end{array}$ & $\begin{array}{r}.02 \\
(2.4) \\
\end{array}$ & $\begin{array}{c}.04 \\
(3.6) \\
\end{array}$ & $\begin{array}{l}.05{ }_{0,1}^{1} \\
(4.2)\end{array}$ & $\begin{array}{l}.11_{0,2}^{0} \\
(6.8)\end{array}$ \\
\hline \multicolumn{7}{|l|}{ Equation statistics: } \\
\hline sample period & $55.1-98.4$ & $55.1-98.4$ & $63.3-98.4$ & $65.3-98.4$ & $55.1-98.4$ & $55.1-98.4$ \\
\hline $\bar{R}^{2}$ & .9305 & .9247 & .8953 & .8786 & .8950 & .8872 \\
\hline SSR & 94.53 & 90.01 & 64.57 & 72.11 & 116.01 & 162.75 \\
\hline regression se & .7501 & .7364 & .6968 & .7535 & .8310 & .9843 \\
\hline Durbin-Watson & 1.61 & 2.01 & 2.09 & 1.53 & 1.74 & 1.79 \\
\hline
\end{tabular}

${ }^{a}$ For each regressor, the estimated coefficient, or coefficient sum, and t-statistic are reported. Entries that are coefficient sums are indicated by subscripts indexing the minimum and maximum lags, and, if polynomial restrictions are imposed, by a superscript reporting the polynomial degree. Equations also include an intercept and wage-price dummy.

${ }^{b}$ The reported t-statistic is associated with the deviation from one of the sum of coefficients on lagged inflation when it is not restricted. 
Table A5

Markup Equations

\begin{tabular}{|c|c|c|c|c|c|c|}
\hline & CPI & $\overline{\mathrm{PCE}}$ & CPIX & PCEX & GDP & NFB \\
\hline $\begin{array}{l}\text { Estimated coefficients: }^{a} \\
\quad \text { inflation lags }\end{array}$ & $\begin{array}{c}1.00{ }_{1,24}^{3} \\
(0.1)\end{array}$ & $\begin{array}{c}1.00 \stackrel{2}{2}, 24 \\
(0.4)\end{array}$ & $\begin{array}{l}1.00{ }_{1,23}^{2} \\
(1.3)\end{array}$ & $\begin{array}{c}1.00_{1,24}^{2} \\
(0.8)\end{array}$ & $\begin{array}{l}1.00{ }_{1,15}^{2} \\
(0.3)\end{array}$ & $\begin{array}{c}1.00{ }_{1,17}^{2} \\
\quad(1.4)\end{array}$ \\
\hline unemployment rate & $\begin{array}{l}-.56_{0,1}^{0} \\
\left(12.0^{)}\right.\end{array}$ & $\begin{array}{l}-.42{ }_{0,1}^{0} \\
(9.4)\end{array}$ & $\begin{array}{l}-.36 \\
(8.7)\end{array}$ & $\begin{array}{l}-.37{ }_{0,3}^{0} \\
(7.3)\end{array}$ & $\begin{array}{l}-.41{ }_{0,1}^{0} \\
(7.4)\end{array}$ & $\begin{array}{l}-.43{ }_{0,1}^{0} \\
(6.9)\end{array}$ \\
\hline $\begin{array}{l}\text { food and energy price } \\
\text { (contemporaneous) }\end{array}$ & $\begin{array}{c}.88 \\
(22.6)\end{array}$ & $\begin{array}{c}.87 \\
(15.7)\end{array}$ & & & $\begin{array}{c}.36 \\
(5.5)\end{array}$ & $\begin{array}{c}.51 \\
(6.5)\end{array}$ \\
\hline $\begin{array}{l}\text { food and energy price } \\
\text { (lags) }\end{array}$ & & & $\begin{array}{l}.41_{1,4}^{0} \\
(7.7)\end{array}$ & $\begin{array}{l}.49_{1,4}^{0} \\
(5.8)\end{array}$ & & \\
\hline farm price & & & & & & $\begin{array}{c}-.02 \\
(8.8)\end{array}$ \\
\hline import price & & $\begin{array}{c}.03 \\
(3.0)\end{array}$ & & & $\begin{array}{l}.04{ }_{0,1}^{1} \\
(3.0)\end{array}$ & $\begin{array}{l}.10_{0,2}^{0} \\
(6.0)\end{array}$ \\
\hline trend markup & $\begin{array}{l}.221,1 \\
(4.9)\end{array}$ & $\begin{array}{l}.251,1 \\
(5.7)\end{array}$ & $\begin{array}{l}.171,1 \\
(3.7)\end{array}$ & $\begin{array}{l}.241,1 \\
(5.0)\end{array}$ & $\begin{array}{l}.191,1 \\
(3.7)\end{array}$ & $\begin{array}{l}.26_{1,1} \\
(4.1)\end{array}$ \\
\hline \multicolumn{7}{|l|}{ Equation statistics: } \\
\hline sample period & $55.1-98.4$ & $55.1-98.4$ & $63.3-98.4$ & $65.3-98.4$ & $55.1-98.4$ & $55.1-98.4$ \\
\hline $\bar{R}^{2}$ & .9430 & .9343 & .9002 & .8899 & .9032 & .8947 \\
\hline SSR & 77.51 & 79.46 & 62.47 & 65.35 & 106.36 & 151.01 \\
\hline regression se & .6793 & .6877 & .6802 & .7174 & .7980 & .9509 \\
\hline Durbin-Watson & 1.83 & 1.69 & 1.88 & 1.63 & 1.84 & 1.82 \\
\hline
\end{tabular}

${ }^{a}$ For each regressor, the estimated coefficient, or coefficient sum, and t-statistic are reported. Entries that are coefficient sums are indicated by subscripts indexing the minimum and maximum lags, and, if polynomial restrictions are imposed, by a superscript reporting the polynomial degree. Equations also include an intercept and wage-price dummy.

${ }^{b}$ The reported t-statistic is associated with the deviation from one of the sum of coefficients on lagged inflation when it is not restricted. 


\section{Data Appendix}

\section{Inflation rates}

Inflation data for CPI, CPIX, PCE, PCEX, GDP and NFB are measured as annualized rates of change in percentage points. Data for CPI and CPIX are modified from 1967 to 1983 to place homeownership costs on a rental-equivalent basis. All inflation series are adjusted to remove effects of recent changes in price measurement methodology. Estimates of methodological effects on CPI and GDP are taken from Council of Economic Advisors (1999, table 2-4). For CPI the reported methodological effects are: 1995, -0.12; 1996, $0.22 ; 1997,-0.23 ; 1998,-0.44$. For GDP the effects are: 1994, -0.06; 1995-98, -0.21. In each case, we add back the effects of methodology changes to create consistently measured inflation time series. We apply the CPI adjustment to CPIX and use adjustments to PCE and NFB that are respectively 1.47 and 1.34 times the adjustment to GDP, where the scaling factors are the average ratios of nominal GDP to nominal PCE and NFB over 1995-98.

Published data starts in 1957:Q1 for CPIX in 1959:Q1 for PCEX, which sets the beginning of the CPIX and PCEX estimation intervals at 1963:Q3 and 1965:Q3, after allowing for a maximum of twenty-five inflation lags. We construct approximate values for CPIX and PCEX for the period prior to the published data for use in defining the food and energy price series. Early values of PCEX are constructed by removing from PCE an estimate of the price of food and energy. For the two components of the latter which are not available before 1959 (electricity and natural gas), estimates of prices are taken from the CPI and estimates of nominal values (needed for chain aggregation) are obtained by interpolating annual data published in various issues of the Survey of Current Business. Early values of the rate of CPIX inflation are estimated by subtracting from CPI inflation fitted values from a regression of the difference between CPI and CPIX inflation on the difference between PCE and PCEX inflation.

\section{Rates of unemployment and capacity utilization}

The demographically fixed-weighted unemployment rate an average of unemployment rates for males and females aged 16-19, males aged 20-24, females aged 20-24, males aged 25 and older, and females aged 25 and older, with weights equal the labor force share of each group in 1993. The final series contains two adjustments. First, 0.08 percentage points is added to the unemployment rate for all dates prior to 1994 to eliminate a discontinuity associated with the 1994 redesign of the Current Population Survey (Polivka and Miller, 
1995). Second, an additional 0.10 percentage point is added to the unemployment rate for all dates prior to 1990 to offset an adjustment associated with the undercount in the 1990 Census (McIntire, 1996). The rate of capacity utilization is for the manufacturing sector.

\section{Food and energy price inflation}

For CPI and CPIX equations, the food and energy price variable is measured as CPI inflation less CPIX inflation. For the other equations, the variable is measured as PCE inflation less PCEX inflation.

\section{Import price inflation}

Equations for CPI, CPIX, PCE, and PCEX contain the annualized rate of increase of the NIPA price of merchandise imports excluding petroleum, computers, and semiconductors. The adjustment for semiconductors makes use of unpublished data from the Bureau of Economic Analysis. Equations for GDP and NFB contain an import price series that is a weighted average of this measure of import price inflation and import price inflation for merchandise excluding only petroleum, with weights of 0.90 and 0.10 , respectively. The weights are based on the nominal ratio of computer final sales to GDP, which averages 0.10 from 1987 to 1998 . Relative import price inflation is constructed by subtracting from the appropriate measure of import price inflation the once-lagged value of the aggregate inflation series being explained.

Data for the price of imports excluding petroleum, computers, and semiconductors is available from 1969:Q3. Earlier values are based on the price of merchandise imports excluding petroleum, an approximation that is probably good given the relative unimportance of trade in computers and semiconductors at that time. The price of merchandise imports excluding petroleum is available only from 1967:Q1, however. Earlier values of both measures of import prices used in the Phillips curves are based on the price of overall imports excluding petroleum (from 1956:Q2) and the price of imports (prior to 1956:Q2).

\section{Trend markup}

The trend markup is $\log (p \rho / w)$, where $p$ is the chain-weight price index for output of the nonfarm business output excluding housing, $w$ is compensation per hour in the nonfarm business sector from the BLS Productivity and Cost release, and $\rho$ is trend labor productivity. The latter is based on the fitted values of a regression of the logarithm of actual labor productivity in the nonfarm sector on a constant, a time trend, and a second time trend that starts in 1973:Q1. The estimation period is 1955:Q1-1998:Q4. Data on $p$ and actual labor 
productivity are adjusted for changes in price measurement methodology by cumulating over time the adjustment to NFB inflation described above. The trend markup is measured relative to its $1955-98$ mean.

\section{Wage-price control variable}

All equations contain a variable that accounts for the effects of wage and price controls in the 1970s. The series, which has a mean of zero, equals 1.0 from 1971:Q3 to 1974:Q1 and -3.67 from 1974:Q2-1974:Q4. 